\title{
Noninvasive Analysis Using Data-Independent Acquisition Mass Spectrometry: New Epidermal Proteins That Reveal Sex Differences in the Aging Process
}

\author{
Shirui Chen $\mathbb{D}^{1,2,3,4,5,6}$ Hui Zhang, ${ }^{1,2,3,4,5,6}$ Mengting Liu, ${ }^{1,2,3,4,5}$ Yaochi Wang, ${ }^{1,2,3,4,5}$ \\ Cong Xin, ${ }^{1,2,3,4,5}$ Jing Ma, ${ }^{1,2,3,4,5}$ Xiaodong Zheng, ${ }^{1,2,3,4,5}$ Xuejun Zhang $\mathbb{D}^{1,2,3,4,5}$ \\ Liangdan Sun $\mathbb{D}^{1,2,3,4,5}$ and Sen Yang $\mathbb{D}^{1,2,3,4,5,6}$ \\ ${ }^{1}$ Department of Dermatology, No. 1 Hospital, Anhui Medical University, Hefei 230032, China \\ ${ }^{2}$ Institute of Dermatology, Anhui Medical University, Hefei 230032, China \\ ${ }^{3}$ Key Laboratory of Dermatology, Anhui Medical University, Ministry of Education, Hefei 230032, China \\ ${ }^{4}$ Anhui Provincial Institute of Translational Medicine, Hefei 230032, China \\ ${ }^{5}$ Inflammation and Immune Mediated Diseases Laboratory of Anhui Province, Hefei 230032, China \\ ${ }^{6}$ Anhui Ferry Dermatological Institute, Hefei 230032, China
}

Correspondence should be addressed to Liangdan Sun; ahmusld@163.com and Sen Yang; yang2004sen@163.com

Shirui Chen and Hui Zhang contributed equally to this work.

Received 13 September 2020; Revised 31 January 2021; Accepted 24 February 2021; Published 9 April 2021

Academic Editor: Alexandros Georgakilas

Copyright (c) 2021 Shirui Chen et al. This is an open access article distributed under the Creative Commons Attribution License, which permits unrestricted use, distribution, and reproduction in any medium, provided the original work is properly cited.

\begin{abstract}
The development of mass spectrometry has provided a method with extremely high sensitivity and selectivity that can be used to identify protein biomarkers. Epidermal proteins, lipids, and cornified envelopes are involved in the formation of the skin epidermal barrier. The epidermal protein composition changes with age. Therefore, quantitative proteomic changes may be indicative of skin aging. We sought to utilize data-independent acquisition mass spectrometry for noninvasive analysis of epidermal proteins in healthy Chinese individuals of different age groups and sexes. In our study, we completed high-throughput protein detection, analyzed protein differences with MaxQuant software, and performed statistical analyses of the proteome. We obtained interesting findings regarding ceruloplasmin (CP), which exhibited significant differences and is involved in ferroptosis, a signaling pathway significantly associated with aging. There were also several proteins that differed between sexes in the younger group, but the sex differences disappeared with aging. These proteins, which were associated with both aging processes and sex differences, are involved in signaling pathways such as apoptosis, oxidative stress, and genomic stability and can serve as candidate biomarkers for sex differences during aging. Our approach for noninvasive detection of epidermal proteins and its application to accurately quantify protein expression can provide ideas for future epidermal proteomics studies.
\end{abstract}

\section{Introduction}

Since 1980, many studies have demonstrated that the epidermis is structurally and biochemically diverse in terms of its metabolic state while playing key roles in epidermal barrier function and skin senescence. Epidermal lipid and protein compositions and the number of stratum corneum (SC) layers affect these processes [1-3]. Skin aging is a complex physiological process in which several mechanisms simulta- neously participate. Both inherent aging and photoaging affect changes in epidermal proteins such as collagen and other extracellular matrix proteins.

In past studies, genomics and transcriptomics have been used to investigate several biological pathways of aging and the expression of human aging-related genes [4-7]. Proteomics research on skin aging is still scarce. Epidermal proteins are involved in the skin barrier [8], and proteomics studies provide more direct information about biological pathways 
than other types of studies. Epidermal proteins continue to change with age [9]. Therefore, research on epidermal proteins can provide insight into biological markers of aging [10]. Many proteins, such as members of the sirtuin family [11], are involved in aging-related signaling pathways. Among these pathways, the most well known are the mTOR, AMPK, WNT, MAPK, and p53 signaling pathways, which ultimately affect the cell cycle, genomic instability, apoptosis, and ultimately the outcome of aging $[12,13]$. There are also differences in the rates of aging between the sexes that may be related to oxidative stress, hormone levels, immunity, and underlying mechanisms related to the sex chromosome [14, 15]. Men have thicker skin than women, but women have thicker subcutaneous tissue than men, and men's skin is more susceptible to environmental stress and UV radiation than women's skin $[16,17]$. Women also generally live longer than men [18], and studies have shown that proteins that change with age also differ between sexes. Notably, aging does not proceed at a linear speed; there are obvious inflection points at different ages, and there are differences between men and women [19]. Many studies thus far have suggested that the speed of aging differs between men and women, so research on sex- and agerelated intersections will be very valuable. Therefore, we evaluated the proteomes of different sexes at different ages and observed whether there were correlations between them.

In this study, we analyzed the differences in the epidermal protein expression profiles of 20 healthy men and women in China with a data-independent acquisition (DIA) method $[20,21]$. We selected the age categories with consideration of the significant changes that occur in the skin during menopause [22]. Noninvasive techniques were used to obtain epidermal proteins and to explore proteins with differences and associations at the levels of both age and sex. To better identify aging-sex correlates, we performed statistical analyses and linked information about these changes to agingrelated signaling pathways. The highlighted proteins may be sex-specific markers of aging, and their identification may help elucidate the reasons for the difference in the rate of aging between men and women.

\section{Materials and Methods}

2.1. Study Participants. Skin samples were collected from 9 healthy Chinese males and 11 healthy Chinese females, none of whom had experienced excessive light exposure. The participants were divided into two groups according to age: the $20-30$ y group ( 3 males and 7 females) and the $55-70$ y group (6 males and 4 females). Individuals were excluded from the study if they had an allergy to tape, were long-term outdoor workers, or had a skin disease or other systemic condition involving skin problems. The participants did not use topical emollients or other cosmetic products for 24 hours prior to the experiment. This study was conducted in accordance with the recommendations of the Medical Ethics Committee of Anhui Medical University, and informed consent was obtained from all enrolled subjects.

2.1.1. Materials. Sodium dodecyl sulfate (SDS), L3 lysate without SDS, trypsin, dithiothreitol (DTT), Coomassie
Brilliant blue G-250, 40\% ethanol, 10\% acetic acid, ethylenediaminetetraacetic acid (EDTA), and acrylonitrile (ACN) were obtained from Wallis Technology, Beijing, China. Ultrafiltration membranes (10K MWCO, $1.5 \mathrm{ml}$, plate) were obtained from Pall Corp. (NY, USA). Pierce C18 pipette tips (10 $\mu \mathrm{l}$ bed), Empore ${ }^{\mathrm{TM}} \mathrm{C} 1847 \mathrm{~mm}$ extraction discs (model 2215), a ThermoMixer (MS-100), and a CentriVap vacuum concentrator and accessories were obtained from Thermo Fisher Scientific (Shanghai, China). The samples were analyzed using a Q Exactive high-frequency mass spectrometer and an UltiMate 3000 high-performance liquid chromatography system (Thermo Fisher Scientific, San Jose, CA, USA).

2.1.2. Sample Preparation. The palm side of the forearm was gently wiped with a sterile cotton ball to cleanse it of epidermal contaminants. A $3.0 * 3.0 \mathrm{~cm}$ piece of a $3 \mathrm{M}$ medical tape was prepared to fully and precisely cover the back of the slide. The slide was then moved back and forth quickly with even pressure for 2 minutes. Even pressure was applied so that the slide was covered. Once the sample was collected, another slide was placed over it to protect the skin sample. To reduce sampling variation, the same technician collected samples from all volunteers during the study.

\subsubsection{Protein Extraction and Enzymolysis}

(1) Protein Extraction. Small pieces $(0.5 \mathrm{~cm} * 0.5 \mathrm{~cm})$ of tape/skin samples were cut out of the slides with a sterile blade and then placed into corresponding $1.5 \mathrm{ml}$ centrifuge tubes according to the sample numbers. An appropriate amount of L3 lysis buffer without SDS was added, and cocktail containing EDTA was added to a final concentration of $\times 1$. The samples were placed on ice for $5 \mathrm{~min}$, and DTT was added to a final concentration of $10 \mathrm{mM}$. The samples were soaked overnight and then centrifuged at 25,000 $\times g$ and $4^{\circ} \mathrm{C}$ for $15 \mathrm{~min}$. The supernatant was obtained, and DTT was added to a final concentration of $10 \mathrm{mM}$. The samples were incubated in a $56^{\circ} \mathrm{C}$ water bath for 1 hour, after which iodoacetamide (IAM) was added to a final concentration of $55 \mathrm{mM}$. The samples were placed in a dark room for $45 \mathrm{~min}$ and then centrifuged at $25,000 \times g$ at $4^{\circ} \mathrm{C}$ for $15 \mathrm{~min}$ to obtain the supernatant, which contained the proteins.

(2) Protein Extraction and Quality Control. The protein concentrations were measured using the Bradford method [23] with acceptable enzymatic efficiency, and it was determined that the extracted protein content was sufficient. For the Bradford quantitative assay, protein standards $(0.2 \mu \mathrm{g} / \mu \mathrm{l}$ BSA; $0,2,4,6,8,10,12,14,16$, and $18 \mu \mathrm{l}$ ) were added to wells A1 through A10 of 96-well MICROLON ELISA plates, and then, pure water $(20,18,16,14,12,10,8,6,4$, and $2 \mu \mathrm{l})$ was added. Then, $180 \mu \mathrm{l}$ of Coomassie Brilliant blue G-250 quantitative work solution was added to each well. A linear standard curve was prepared based on the optical density at $595 \mathrm{~nm}$ (OD595) and the protein concentration. The protein sample solutions were diluted several times, $180 \mu \mathrm{l}$ of the quantitative solution was added to $20 \mu \mathrm{l}$ of protein solution, and the OD595 was read. The protein concentration of each sample was calculated according to the standard curve and 
the sample OD595. The purity of the extracted proteins was verified by SDS-PAGE and Coomassie Brilliant blue staining.

(3) SDS-PAGE. For each sample, $30 \mu \mathrm{g}$ of protein was added to an appropriate amount of loading buffer. After thorough mixing, the proteins in buffer were heated at $95^{\circ} \mathrm{C}$ for $5 \mathrm{~min}$, centrifuged at $25,000 \times g$ for $5 \mathrm{~min}$, and placed into the wells of a $12 \%$ SDS polyacrylamide gel. After electrophoresis, Coomassie Brilliant blue staining was conducted for 2 hours. An appropriate amount of decolorization solution (40\% methanol and 10\% acetic acid) was added to each sample, and the samples with decolorization solution were placed in a shaker 3 to 5 times for $30 \mathrm{~min}$ each.

(4) Proteolysis. Trypsin $(2.5 \mu \mathrm{g})$ was added to $100 \mu \mathrm{g}$ of protein for each sample at a protein: enzyme ratio of $40: 1$, and the protein was hydrolyzed at $37^{\circ} \mathrm{C}$ for 4 hours. Trypsin was added once more according to the above ratio, and enzymolysis was continued for 8 hours at $37^{\circ} \mathrm{C}$. The enzymatically digested peptides were desalted with a Strata-X column and extracted under vacuum. With this method, we extracted sufficient amounts of proteins with qualified enzymatic efficiency.

2.1.4. High-pH Reverse-Phase Separation. A pooled sample was created from $10 \mu \mathrm{g}$ of each sample, and $200 \mu \mathrm{g}$ of the pooled sample was mixed with $2 \mathrm{ml}$ of mobile phase A (5\% acetonitrile, ACN, pH 9.8) and diluted into a Shimadzu LC$20 \mathrm{AB}$ liquid chromatography system. The samples were separated in a liquid phase on a $5 \mu \mathrm{m} 4.6 \times 250 \mathrm{~mm}$ Gemini C18 column. Elution was conducted at a flow rate of $1 \mathrm{ml} / \mathrm{min}$ with the following gradient: $5 \%$ mobile phase B $(95 \% \mathrm{ACN}$, $\mathrm{pH} 9.8$ ) for $10 \mathrm{~min}, 5 \%$ to $35 \%$ mobile phase B for $40 \mathrm{~min}$, $35 \%$ to $95 \%$ mobile phase B for $1 \mathrm{~min}$, mobile phase B which lasted for $3 \mathrm{~min}$, and equilibration at $5 \%$ mobile phase B for $10 \mathrm{~min}$. The elution peaks were monitored at $214 \mathrm{~nm}$, and one fraction was collected every minute. The samples were combined with the chromatogram elution peaks to obtain 10 fractions, which were then extracted by freezing.

2.1.5. High-Performance Liquid Chromatography. The extracted peptide samples were redissolved (centrifuged with mobile phase A (2\% ACN and $0.1 \%$ formic acid (FA)) at $20,000 \times g$ for $10 \mathrm{~min}$ ), and the supernatant liquid was sampled. Separation was performed with a Thermo UltiMate 3000 UHPLC. Each sample was first injected into a trap column for enrichment and desalting before being run through a self-loading C18 column ( $150 \mu \mathrm{m}$ I.D., $1.8 \mu \mathrm{m}$ pore size, $25 \mathrm{~cm}$ column length) coupled to tandem mass spectrometers. The samples were separated at a flow rate of $500 \mathrm{nl} / \mathrm{min}$ through the following effective gradient: 0-5 min, 5\% mobile phase B (98\% ACN, 0.1\% FA); 5-160 min, linear increase in mobile phase B from $5 \%$ to $35 \%$; $160-170 \mathrm{~min}, 35 \%$ to $80 \%$ mobile phase $\mathrm{B}$; $170-175 \mathrm{~min}, 80 \%$ mobile phase $\mathrm{B}$; and $176-$ $180 \mathrm{~min}, 5 \%$ mobile phase $\mathrm{B}$. The output of the liquid chromatograph was connected directly to the mass spectrometer.

2.1.6. Data-Dependent Acquisition (DDA) and DataIndependent Acquisition (DIA) Mass Spectrometry Analyses.
After liquid chromatography, the peptides were separated by nanoelectrospray ionization (ESI) and detected in a DDA mode with a Q Exactive HF (Thermo Fisher Scientific, San Jose, CA) tandem mass spectrometer. The main parameter settings were as follows: the ion source voltage was $1.6 \mathrm{kV}$, the primary mass spectrometer range was $350 \sim 1,500 \mathrm{~m} / \mathrm{z}$, the resolution was 60,000 , the MS2 starting $\mathrm{m} / \mathrm{z}$ was fixed at 100 , and the resolution of the second-stage mass spectrometer was 15,000 . The screening criteria for the precursor ions in the MS2 scans were a charge of $2+$ to $7+$ with a peak intensity of over 10,000 and a ranking in the top 20. The main parameter settings for DIA mode detection were as follows: the ion source voltage was $1.6 \mathrm{kV}$, the MS1 scanning range was $350-1,500 \mathrm{~m} / \mathrm{z}$ with a resolution of 120,000 , and the $350-1,500 \mathrm{Da}$ range was divided into 40 windows for fragmentation and signal acquisition. Higherenergy collisional dissociation (HCD) was used for the DDA and DIA modes of mass spectrometric detection of ion fragmentation patterns. The fragmented ions were detected in an Orbitrap. The dynamic exclusion time was set to $30 \mathrm{~s}$. The automatic gain control (AGC) settings were as follows: level 1: 3E6 and level 2: 1E5.

2.2. Analysis of Epidermal Proteomics Data. The DDA data from the machine were identified using the Andromeda search engine integrated with MaxQuant [24], and Spectronaut was then used to build a spectral library with the results. The resulting data were reviewed using the UniProtKB/Swiss-Prot Homo sapiens proteome database. For large-scale DIA data, after constructing the spectral library information, convolutional extraction of the data was completed using Spectronaut, and data analysis and quality control were completed using the mProphet algorithm, resulting in reliable protein quantification results. Gene Ontology (GO) and Kyoto Encyclopedia of Genes and Genomes (KEGG) pathway functional annotations were performed. Based on the high-quality quantitative results, we searched for differentially expressed proteins (DEPs) between groups.

MaxQuant was used to complete the identification of the DDA data in order to create the spectral library for subsequent DIA data analysis. During this procedure, the original offline data were used as the input data, the corresponding parameters and database were configured, and then, the identification and quantitative analysis were performed. The identification information that met the criterion of a false discovery rate $(F D R) \leq 1 \%$ was used to build the final spectral library. The offline DIA data were analyzed using Spectronaut [25], and iRT peptides were used to correct the retention time. Spectronaut integrates the mProphet scoring algorithm, which can accurately reflect the degree of matching of isolated pairs. Then, based on the target-decoy model applied by SWATH-MS, the false-positive rate was controlled at $1 \%$ FDR, which yielded significant quantitative results.

This procedure was used to preprocess the data according to the set comparison group, and a significance test was then performed based on the model. After that, the DEPs were screened with the criteria of a fold change (FC) value $\geq 1.5$ and a $p$ value $<0.05$ (the top 10 DEPs are listed in Table 1). The R package MSstats [26] from the Bioconductor 
TABLE 1: Top 10 differentially expressed proteins.

\begin{tabular}{|c|c|c|c|c|c|c|}
\hline & \multicolumn{3}{|c|}{ Upregulated } & \multicolumn{3}{|c|}{ Downregulated } \\
\hline & Protein ID & $\log ^{2} F C$ & $p$ value & Protein ID & $\log ^{2} \mathrm{FC}$ & $p$ value \\
\hline \multirow{10}{*}{ Old vs young } & LG3BP & 0.700 & 0.001 & ABRX2 & -0.750 & 0.001 \\
\hline & HBA & 3.606 & 0.001 & PLD3 & -0.698 & 0.003 \\
\hline & RENR & 1.014 & 0.001 & VTI1B & -0.587 & 0.004 \\
\hline & APOA2 & 3.069 & 0.001 & VAT1 & -0.783 & 0.004 \\
\hline & CLUS & 1.667 & 0.001 & KRT35 & -1.645 & 0.004 \\
\hline & SG1D2 & 2.661 & 0.002 & BAF & -2.492 & 0.005 \\
\hline & SEM7A & 1.414 & 0.002 & ECM1 & -0.631 & 0.009 \\
\hline & B2MG & 1.590 & 0.002 & $\mathrm{~K} 1 \mathrm{C} 15$ & -0.600 & 0.010 \\
\hline & S10A4 & 0.734 & 0.002 & MYH9 & -0.907 & 0.011 \\
\hline & $\mathrm{HBB}$ & 3.462 & 0.003 & PSB7 & -0.678 & 0.012 \\
\hline
\end{tabular}

resource library was used to complete differential analysis of the DEPs.

2.3. Screening for DEPs. After the raw data were mediannormalized by the software, the resulting data were selected for follow-up analysis. DEPs were identified through symmetrical scatter plot screening. The dots represent the relative mean expression values (normalized and $\log ^{2}$ transformed) of the proteins in the two groups, and the $\log ^{2}$ (FC) values were calculated using the $\mathrm{R}$ package MSstats. The dashed line in the graph represents the threshold line at $\left|\log ^{2}(\mathrm{FC})\right|=1.5$ . Thus, the volcano plot of DEPs was produced with the average protein expression values, $\log ^{2}$ (FC) values, and $p$ values. The color of the dot for each protein indicates the significance of the $p$ value, with the blue to red gradient indicating $p$ values ranging from nonsignificant to significant. The graph shows information about the gradient change. We performed protein-protein interaction network analysis on all the DEPs and screened the proteins with more than 10 nodes of neighboring proteins in the protein relationship network. The proteins with the most significant differences in $\log ^{2}$ (FC) values and $p$ values were also selected (Table 2). A gene-level network analysis was conducted for the selected most promising candidate proteins, and the biological pathways in which they were enriched were investigated by using NetworkAnalyst 3.0 inline tool $[27,28]$, the value of the interaction relationship between genes retained the interaction relationship with experimental evidence, and the confidence score cutoff is set to 900. In addition, to observe the correlations between our differential expression analysis data and other aging-related proteomics results in external databases, we compared the DEP data with data from the Human Aging Gene Database (https://genomics.senescence.info/ genes/index.html) (last updated on February 9, 2020) and from plasma proteomics studies related to aging changes in healthy populations [29].

2.4. Independent Sample t-Tests for within-Age Group Differences. Information was compiled on the DEPs identified in the age groups in the DIA experiment. To reduce error caused by NA values in the experimental data, SPSS 25.0 software was used to perform independent sample $t$-tests for the different age groups. Only when a $p<0.05$ between age groups was obtained were independent sample $t$-tests performed between the male and female subgroups within the age groups. Both the $p$ value and the average value of protein expression were recorded for the different sexes. GraphPad Prism 8.3.0 was used to create violin plots of the proteins with significant differences in the $t$-tests in order to better visualize the distribution of the data and the differences in expression between sexes. GraphPad was also used to generate receiver operating characteristic (ROC) curves and heatmaps for selected DEPs.

\section{Results}

3.1. Protein Quantification and Data Quality Control. In this project, mass spectrometry data were collected for 20 samples using a Q Exactive HF instrument in the DIA mode. Peptide quantification and protein quantification were completed using Spectronaut and MSstats software. The specific quantitative information for each sample is shown in Figures 1(d) and 1 (e). In total, we identified 1,318 proteins in the 20 samples, which were further analyzed with MSstats software, resulting in 1,270 proteins. The quality of the data was assessed by analysis of intragroup coefficients of variation, principal component analysis, and quantitative sample correlation analysis. We calculated Pearson's correlation coefficients for the expression levels of all protein expressions between the two groups and displayed these coefficients as a heat map, as shown in Figure 2(b). We also acquired DDA mass spectrometry data from the samples and then used MaxQuant to complete library identification in order to obtain nonredundant, high-quality MS/MS spectral information for subsequent quantification in the DIA mode. The spectral library contained fragment ion intensities and retention times, which characterized the peptide spectral peaks. With regard to statistical information for the peptides and proteins in the spectral library, we obtained the peptide distribution, protein amount distribution, and protein coverage distribution (Figures 1(a)-1(c)).

3.2. Identification of 95 DEPs in Aging via Proteomics Analysis. In order to obtain quantitative proteomic maps of 
TABLE 2: Functional role of the 21 proteins.

\begin{tabular}{|c|c|c|c|c|}
\hline $\begin{array}{l}\text { Protein } \\
\text { ID }\end{array}$ & UniProt & Gene symbol & Full name & Function \\
\hline HBB & P68871 & HBB & $\begin{array}{l}\text { Hemoglobin subunit } \\
\text { beta }\end{array}$ & This protein includes iron ion binding and oxygen binding \\
\hline HBA & P69905 & HBA1, HBA2 & $\begin{array}{l}\text { Hemoglobin subunit } \\
\text { alpha }\end{array}$ & $\begin{array}{l}\text { Involved in oxygen transport from the lung to the various peripheral } \\
\text { tissues }\end{array}$ \\
\hline APOA2 & P02652 & APOA2 & Apolipoprotein A-II & $\begin{array}{l}\text { May stabilize the HDL (high-density lipoprotein) structure by its } \\
\text { association with lipids and affect the HDL metabolism }\end{array}$ \\
\hline VAT1 & Q99536 & VAT1 & $\begin{array}{l}\text { Synaptic vesicle } \\
\text { membrane protein }\end{array}$ & $\begin{array}{l}\text { Possesses ATPase activity (by similarity) and plays a part in calcium- } \\
\text { regulated keratinocyte activation in epidermal repair mechanisms }\end{array}$ \\
\hline LG3BP & Q08380 & LGALS3BP & $\begin{array}{l}\text { Galectin-3-binding } \\
\text { protein }\end{array}$ & $\begin{array}{c}\text { Promotes integrin-mediated cell adhesion and may stimulate host } \\
\text { defense against viruses and tumor cells }\end{array}$ \\
\hline KRT35 & Q92764 & KRT35 & $\begin{array}{l}\text { Keratin, type I } \\
\text { cuticular Ha5 }\end{array}$ & A member of the keratin gene family \\
\hline $\mathrm{ABRX} 2$ & Q15018 & ABRAXAS2/FAM175B & $\begin{array}{l}\text { BRISC complex } \\
\text { subunit Abraxas } 2\end{array}$ & $\begin{array}{l}\text { Required for normal induction of p53/TP53 in response to DNA } \\
\text { damage }\end{array}$ \\
\hline BAF & O75531 & BANF1 & $\begin{array}{l}\text { Barrier-to- } \\
\text { autointegration factor }\end{array}$ & $\begin{array}{l}\text { Plays fundamental roles in nuclear assembly, chromatin organization, } \\
\text { gene expression, and gonad development }\end{array}$ \\
\hline G3P & P04406 & GAPDH & $\begin{array}{c}\text { Glyceraldehyde-3- } \\
\text { phosphate } \\
\text { dehydrogenase }\end{array}$ & $\begin{array}{l}\text { The product of this gene catalyzes an important energy-yielding step } \\
\text { in carbohydrate metabolism }\end{array}$ \\
\hline APOA1 & P02647 & APOA1 & Apolipoprotein A-I & $\begin{array}{l}\text { This protein is associated with the transport of cholesterol and the } \\
\text { major protein component of high-density lipoprotein (HDL) }\end{array}$ \\
\hline HPT & P00738 & $\mathrm{HP}$ & Haptoglobin & $\begin{array}{l}\text { This protein produces haptoglobin, which encodes a protein with } \\
\text { antimicrobial activity against bacteria }\end{array}$ \\
\hline CLUS & P10909 & CLU & Clusterin & $\begin{array}{l}\text { This protein is involved in several basic biological events such as cell } \\
\text { death, tumor progression, and neurodegenerative disorders }\end{array}$ \\
\hline A1AG1 & P02763 & ORM1 & $\begin{array}{l}\text { Alpha-1-acid } \\
\text { glycoprotein } 1\end{array}$ & $\begin{array}{l}\text { This protein is classified as an acute-phase reactant and may be } \\
\text { involved in aspects of immunosuppression }\end{array}$ \\
\hline A2MG & P01023 & $\mathrm{A} 2 \mathrm{M}$ & $\begin{array}{l}\text { Alpha-2- } \\
\text { macroglobulin }\end{array}$ & $\begin{array}{l}\text { This gene can inhibit inflammatory cytokines and thus disrupts } \\
\text { inflammatory cascades }\end{array}$ \\
\hline CYTC & P01034 & CST3 & Cystatin-C & This protein was shown to have an antimicrobial function \\
\hline FIBG & P02679 & FGG & $\begin{array}{l}\text { Fibrinogen gamma } \\
\text { chain }\end{array}$ & $\begin{array}{c}\text { The protein encoded by this gene is the gamma component of } \\
\text { fibrinogen }\end{array}$ \\
\hline CERU & P00450 & $\mathrm{CP}$ & Ceruloplasmin & A glycoprotein with ferroxidase activity \\
\hline FIBA & P02671 & FGA & $\begin{array}{l}\text { Fibrinogen alpha } \\
\text { chain }\end{array}$ & $\begin{array}{c}\text { This gene encodes the alpha subunit of the coagulation factor } \\
\text { fibrinogen }\end{array}$ \\
\hline ANT3 & P01008 & SERPINC1 & Antithrombin-III & A member of the serpin superfamily and a plasma protease inhibitor \\
\hline FIBB & P02675 & FGB & Fibrinogen beta chain & The protein encoded by this gene is the beta component of fibrinogen \\
\hline VTDB & P02774 & GC & $\begin{array}{l}\text { Vitamin D-binding } \\
\text { protein }\end{array}$ & $\begin{array}{l}\text { Involved in vitamin } \mathrm{D} \text { transport and storage and scavenging of } \\
\text { extracellular G-actin }\end{array}$ \\
\hline
\end{tabular}

the stratum corneum of keratinocytes derived from elderly and young populations, we used data extracted from MaxQuant and Spectronaut convolutions and applied bioinformatics analysis using 1\% FDR analysis to identify 95 unique proteins that were differentially expressed between the age groups. The supplementary tables show important information about the identified proteins, including their UniProtKB accession numbers, IDs, protein and gene names, adjusted $p$ values, and associated functions. The proteins that were significantly differentially expressed according to age included 38 downregulated proteins and 57 upregulated proteins (Supplementary Table 1 and Supplementary Table 2). In an interaction analysis of the 95 DEPs, we counted the proteins with more than 10 nodes of protein interactions (Figure 3(a)). We compared our DEPs with 307 human aging-related genes from the GenAge database and identified 6 genes that intersected with the DEPs, namely, CDC42, CLU, A2M, LMNA, VCP, and AIFM1 (Figure 4(c)). In a proteomics study on the senescence-associated secretory phenotype [30], serine protease inhibitors (SERPINs) were shown to be significantly associated with age changes in human cohorts and to be potential biomarkers. In the induced aging model in that study, the secretion levels of the proteins SERPINE1, SERPINF1, SERPINF2, SERPING1, and SERPINH1 were significantly increased. In contrast, SERPINA3, SERPINB1, SERPINB6, and SERPINC1 were 


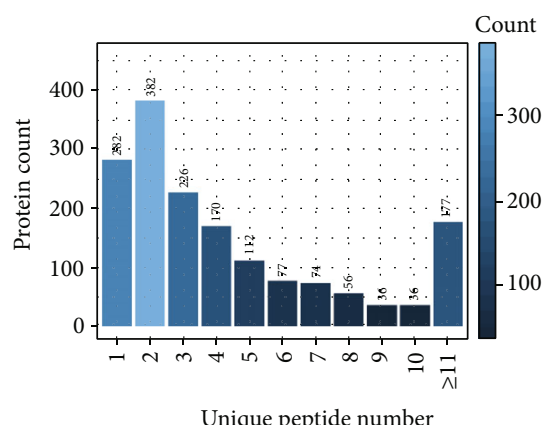

(a)

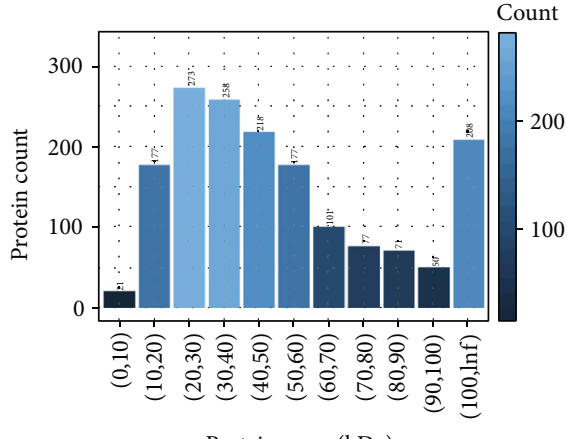

Protein mass $(\mathrm{kDa})$

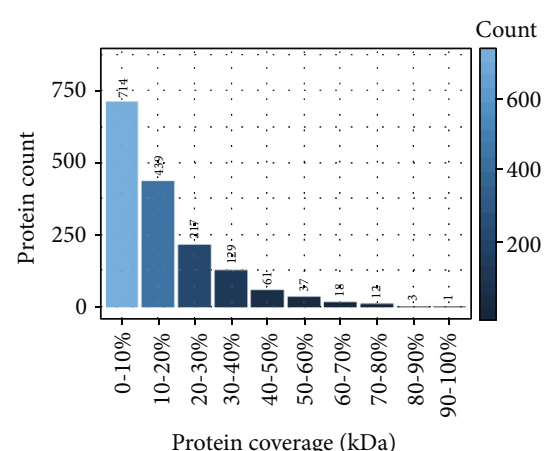

(c)

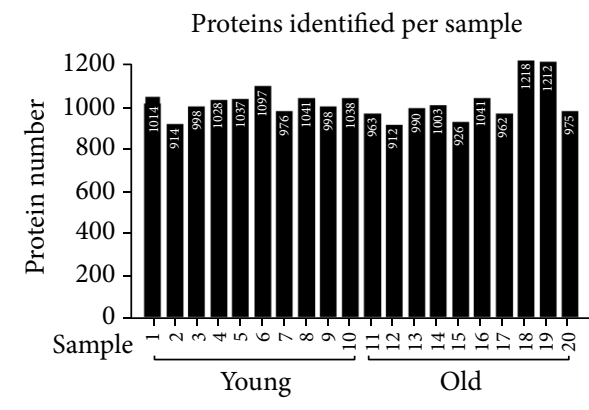

(d) (b)

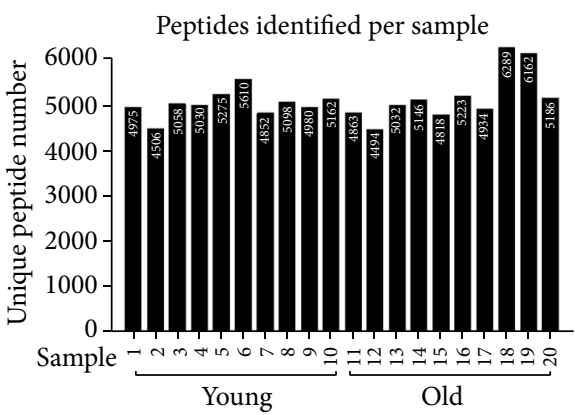

(e)

FIGURE 1: (a) Identification of DDA profiles for subsequent DIA quantification: unique peptide distribution with the horizontal axis being the only matching peptide number per protein and the vertical axis being the number of proteins; (b) protein mass distribution with the horizontal axis being the protein mass interval (Kilodalton) and the vertical axis being the corresponding protein number; (c) protein coverage distribution with the horizontal axis being the percentage protein coverage interval and the vertical axis being the number of proteins. (d, e) Unique proteins and peptides were counted in each sample collected by Q Exactive HF in the DIA mode.

significantly upregulated with age in our study. In an ageassociated proteomics study in a healthy population [29], 217 age-associated proteins were present, 9 of which intersect with the DEPs in our study: ANXA2, S100A4, B2M, FGA, FGB, FGG, SERPINA3, CST3, and HP (Figure 4). In the previous study, SERPINA3 and SERPING1 were positively correlated with age, while SERPINF2 was negatively correlated with age, which is consistent with our results.

\subsection{Functional Analysis of the DEPs. Through DIA mass} spectrometry, we identified a total of 1,270 unique proteins, of which 95 were differentially expressed in the different age groups. The 95 identified proteins were analyzed using the GO and KEGG databases (the functional classifications of the 95 DEPs are shown in Supplementary Table 3). The functional pathways into which the DEPs were classified are shown in Figure 5(a) including the cellular process, environmental information processing, genetic information processing, human disease, metabolism, and organismal system pathways. We analyzed the DEPs with the KEGG and found that the most enriched pathways included platelet activation, complement and coagulation cascades, and the VEGF signaling pathway. Among the DEPs, BANF1 was found to be responsible for the chromatin structure and dynamics, replication, recombination, and repair. Energy production and transfer are also entry points for the aging process, and LDHB and HBAl were enriched in these pathways. The signaling pathways that we focused on in relation to aging included ferroptosis and apoptosis, both of which are cell growth- and death-related metabolic pathways. Among the six proteins intersecting with GenAge data, AIFM1 and LMNA are involved in apoptosis. In the gene-level network analysis of the 21 most promising proteins we screened (Figures 3(b)-3(e)), the significantly enriched pathways were the complement and coagulation cascades, platelet activation, ferroptosis, apoptosis, autophagy, and PPAR signaling pathways. Among them, the PPAR signaling pathway may be closely related to the aging process [31]. (For more detailed gene node information, please refer to Supplementary Tables 4, 5, 6, 7, and 8 and the following website: https://www.networkanalyst.ca/NetworkAnalyst/ faces/Share?ID=_9qljssi8x.) A protein of particular interest was ceruloplasmin $(\mathrm{CP})$, which had 16 neighboring proteins in the protein-protein interaction network. $\mathrm{CP}$ is closely associated with aging $[32,33]$, and the biological metabolic pathway in which it participates is the well-known ferroptosis pathway (Figure 6), a signaling pathway that is closely associated with aging. Our age-associated proteomics results are consistent with the results obtained in other age-associated proteomics studies with independent cohorts (Supplementary Tables 1 and 2 at 10.1038/s41591-019-0673-2).

3.4. Potential Candidate Biomarkers of Sex Differences in the Aging Process. We compared the proteins that changed most significantly under the influence of two factors, age and sex, according to a dual statistical threshold defined by the $p$ value 

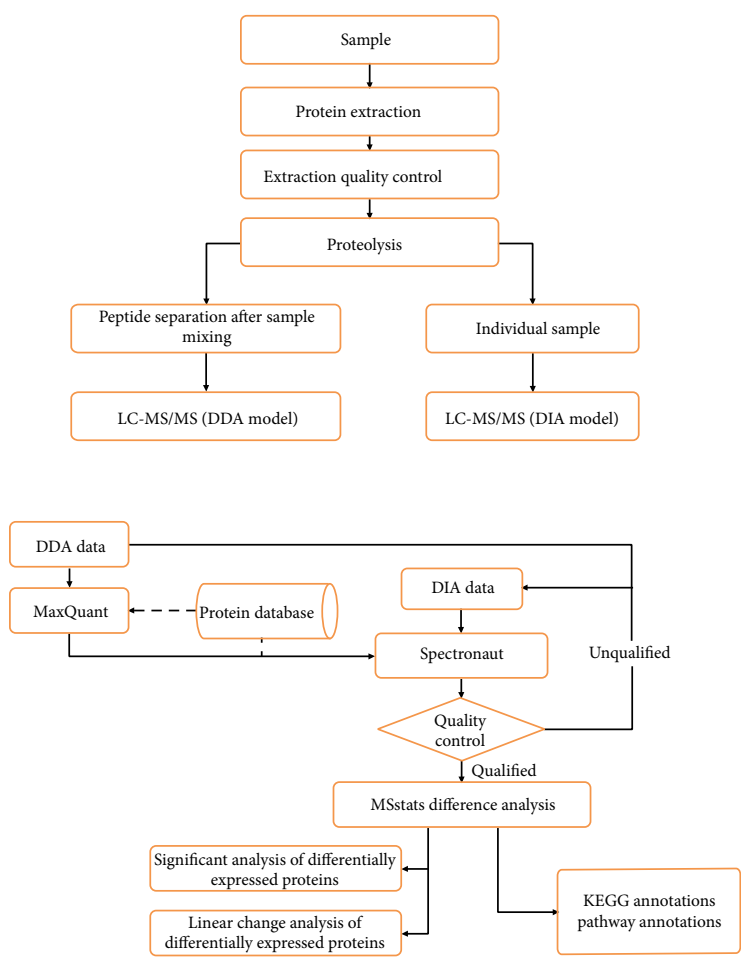

(a)

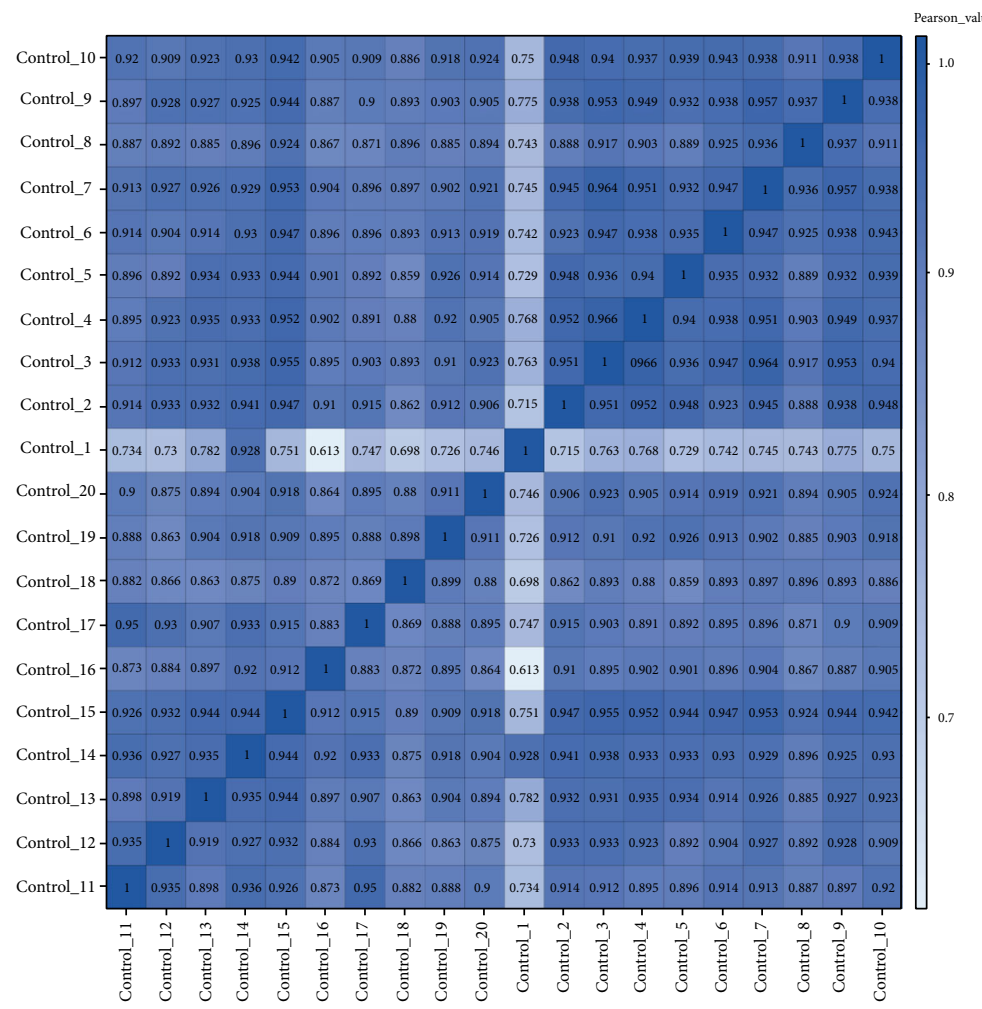

(b)

FIGURE 2: (a) Flowchart of protein extraction, enzymatic hydrolysis experiments, and information analysis. (b) The $x$-axis and $y$-axis of both samples. Color represents the correlation coefficient (the bluer the color, the higher the correlation and the lighter the color, the lower the correlation). 


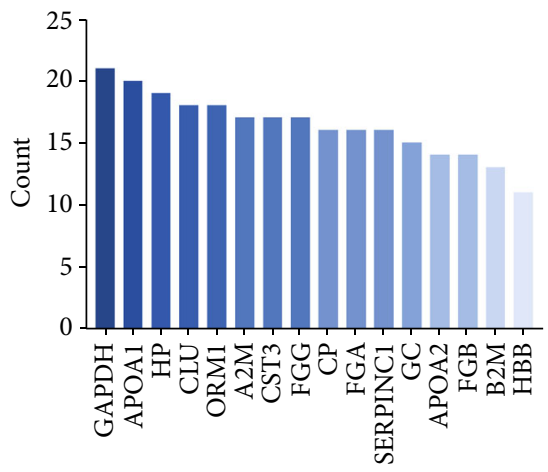

(a) VRK1

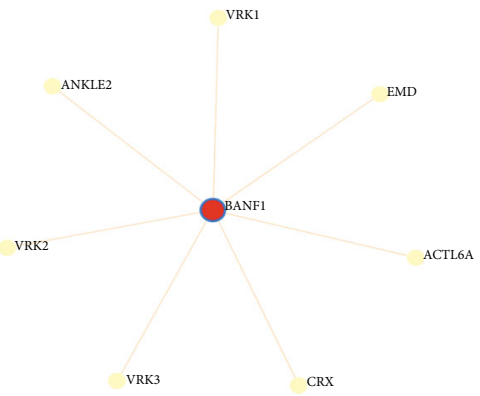

(c)

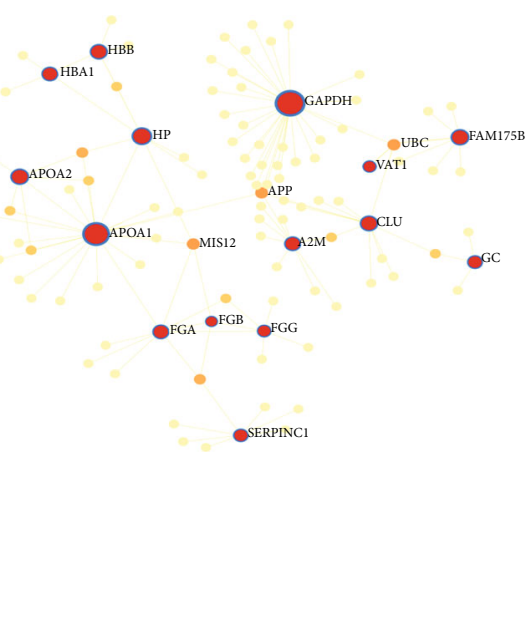

(b)
SLC11A2

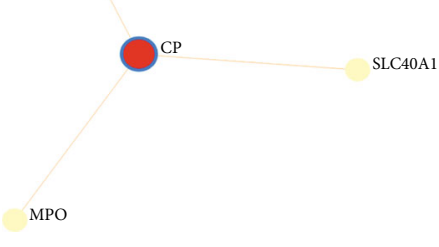

(d)

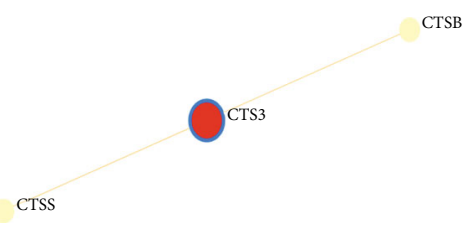

(e)

FIGURE 3: (a) Proteins possessing more than 10 neighboring proteins in the protein-protein interaction network analysis. (b-e) Network analysis of gene expression was performed for the 21 selected genes, where the genes we selected were indicated by red circles. The pathway with the most genes involved in (b) is complement and coagulation cascades; the pathway with the most genes involved in (c) is cardiomyopathy; the pathway with the most genes involved in (d) is ferroptosis; and the pathway with the most genes involved in (e) is apoptosis and autophagy. (Supplementary Tables 5, 6, 7, and 8 for details).

and $\log ^{2}(\mathrm{FC})$. The proteins that were most significantly upregulated in the elderly group were LGALS3BP, HBA1, and $\mathrm{HBB}$, while the proteins that were most significantly upregulated in the young group were ABRAXAS2, BANF1, VAT1, and KRT35 (Figure 4(a)). The proteins in the graph are colored according to the significance of the $p$ value, and the graph clearly shows that a smaller $p$ value was associated with a greater difference in protein expression between the groups. Women generally live longer than men [18], and aging rates differ between men and women [34]. From the 95 proteins identified in our quantitative proteomics experiments and through statistical analysis via independent sample paired $t$-tests between the age and sex groups, we selected proteins as candidate biomarkers for distinguishing differences in the aging process between men and women (Figure 7). The ROC curves of several proteins of interest are shown in Figure 8, and the corresponding area under the curve (AUC) values and $p$ values were calculated. ABRAXAS2, VAT1, and LGALS3BP were identified as promising candidate biomarkers of aging. $t$-tests for these three proteins revealed a $p$ value $<0.05$ between men and women in the younger group and a $p$ value $>0.05$ between men and women in the older group (Table 3 ). Thus, the three proteins were expressed differently between sex groups in the young population, but this difference disappeared with aging. Among these proteins, ABRAXAS2 and VAT1 were downregulated in the elderly group and LGALS3BP was upregulated in the elderly group. The results of tandem mass spectrometry of the three proteins are shown in Figures 9(a)-9(c).

\section{Discussion}

The process of skin aging is very complicated. In addition, due to differences in hormone levels and the immune system, there are also differences in the aging process between men and women $[18,35,36]$. The expression of epidermal proteins can be decrypted using proteomics techniques with DIA. This study is aimed at identifying and quantifying proteins that were differentially expressed at different ages while looking for key information regarding the differences between different sexes during aging. Reliable statistical analysis techniques revealed that 95 proteins were significantly differentially expressed according to age; of these, 57 were upregulated with aging and 38 were downregulated with aging.

The results of this study are consistent with those of previous studies, which confirms the reliability of our proteomics experimental data. In our study, the results for SERPIN protein family members, FGA, FGB, FGG, and other 


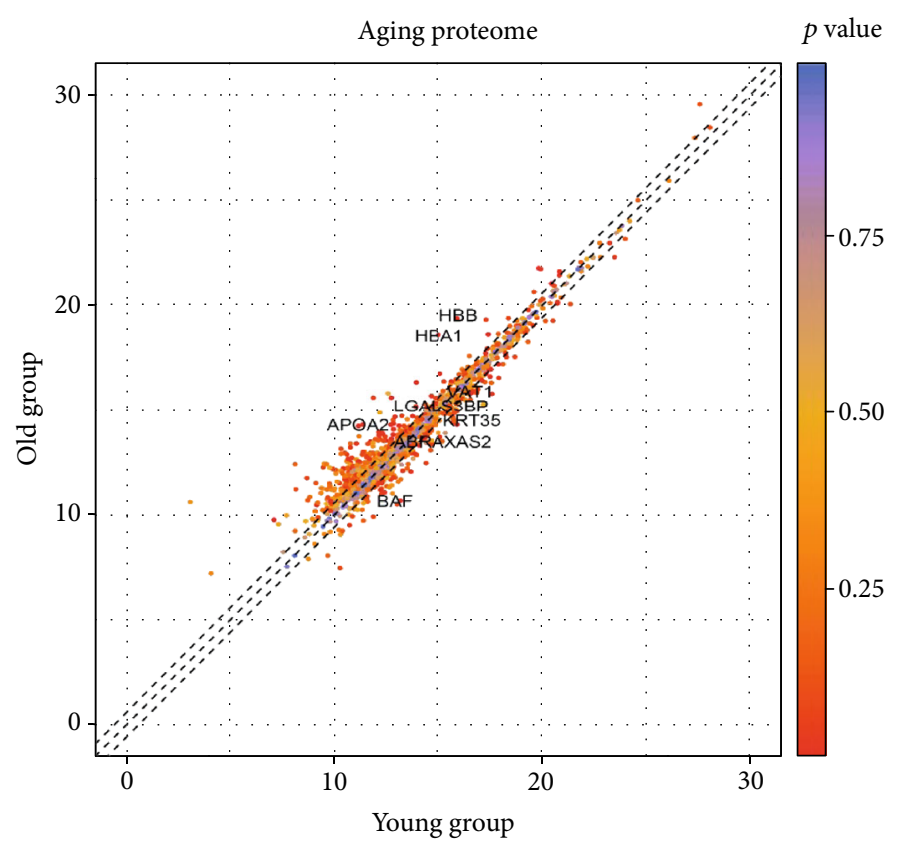

(a)

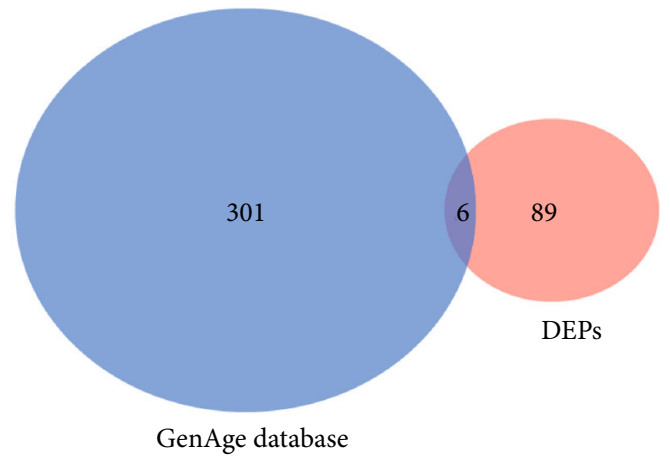

(c)

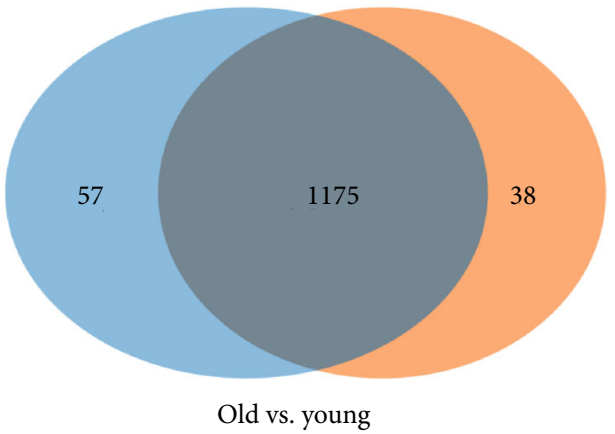

(b)

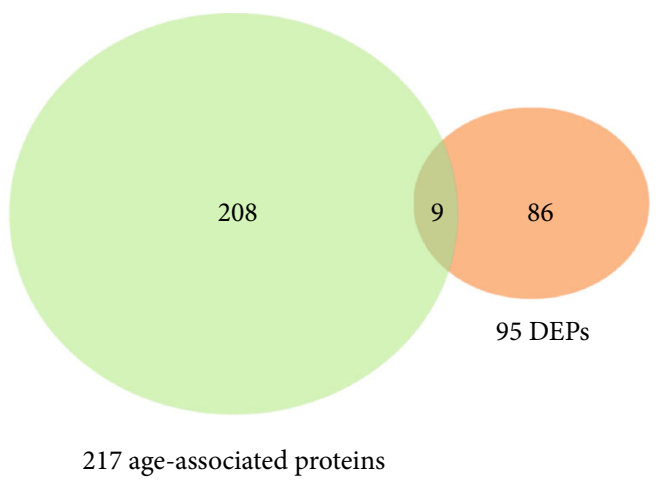

(d)

Figure 4: (a) Symmetric scatter plots compare the differential status of proteins in the age group. The horizontal and vertical coordinates represent the mean relative expression of young and old groups; the dashed line in the graph represents the threshold line at $\left|\log ^{2} \mathrm{FC}\right|=$ 1.5. The color of the scatter represents the $p$ value. (b) Wayne plots show the distribution of protein expression between the young and old groups, with coverage areas representing differentially expressed proteins. (c) Wayne diagram of our proteomic results and 307 genes from the GenAge Human Aging Gene Database. (d) Venn diagram of our proteomic results and an aging-related plasma proteomics study in a healthy population.

proteins were consistent with other aging-related proteomics findings. Xu et al. found that low expression of SERPINC1 may suppress the PI3K/AKT/mTOR signaling pathway [37] and the suppression of the PI3K/AKT/mTOR signaling pathway can delay aging [38]. We also obtained some results that differ from previous findings, such as the results regarding the expression of GPC1 protein; in previous studies, GPC1 has been found to be significantly downregulated with aging [39], while it was upregulated with aging in our study. This difference between studies may have been related to sample size differences, laboratory errors, etc. The results of pathway enrichment analysis showed that the most enriched pathway was platelet activation [40]. There is evidence that oxidative stress contributes to the high reactivity of platelet activation during aging. FGA, FGB, FGG, VASP, and SNAP23 detected in the skin are all related to this pathway. In addition, another pathway, glycerophospholipid metabolism, was noteworthy, as metabolic dysfunction is a common feature of the aging mechanism [41]. The VEGF signaling pathway was also of interest. As age increases, the blood flow in the dermal blood vessels decreases, which leads to decreases in the proliferation of skin fibroblasts that may be related to impairment of the VEGF signaling pathway [42]. Finally, energy production and conversion are also related to the aging of cells [43]. One of the proteins involved in these processes is GPD2, which helps block the IMPM2L-GPD2 and IMMP2L-AIF signaling axes in order to drive the aging process instead of cell death under oxidative stress [44]. One study has shown that activation of respiratory chain-related GPD2 increases reactive oxygen species (ROS) release from mitochondria 


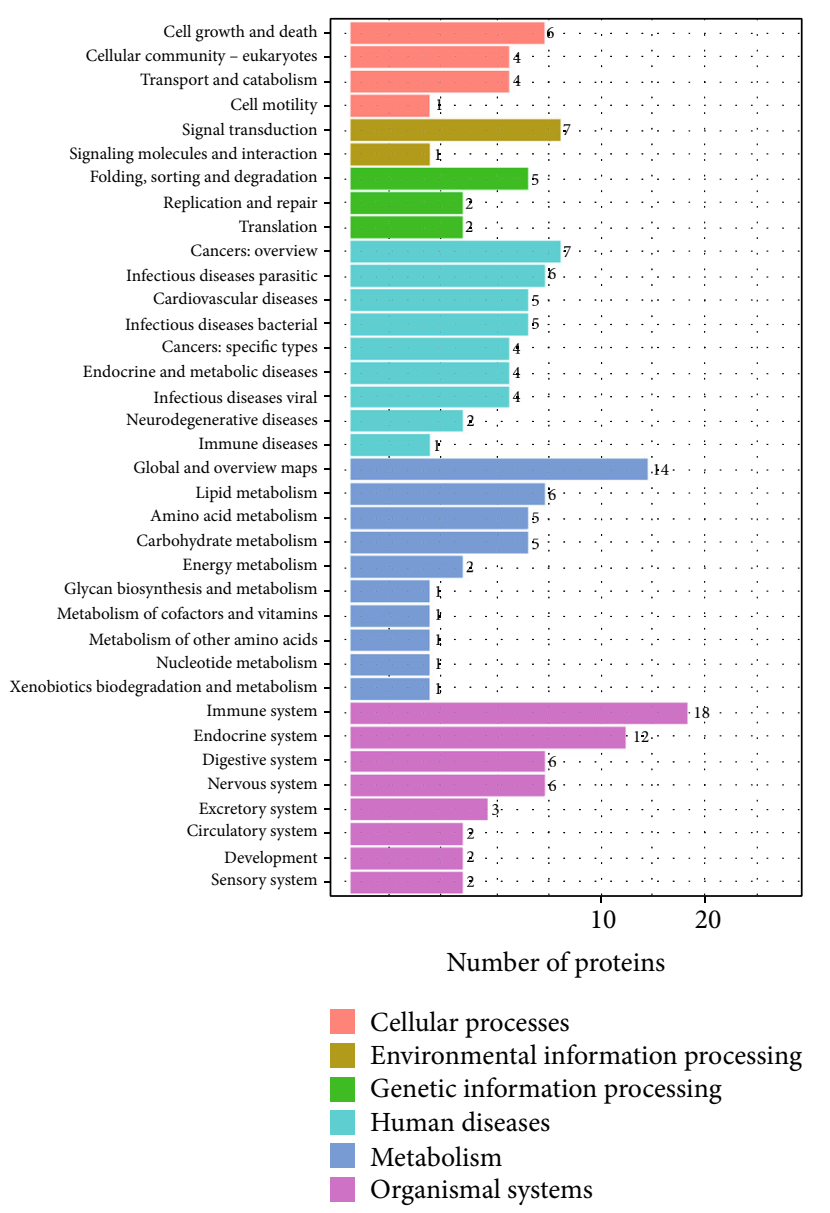

(a)

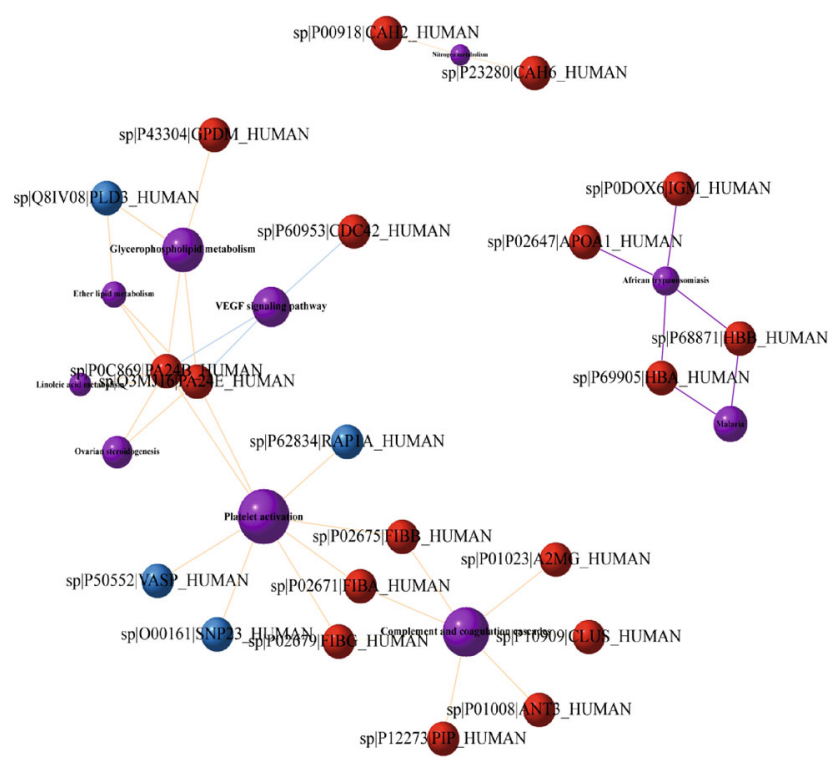

(b)

Figure 5: (a) Pathway classification of differentially expressed proteins, the $x$-axis represents the number of differentially expressed proteins, the $y$-axis represents the pathway-annotated entries. (b) Pathway relationships; red and blue dots indicate up-and downregulated differential proteins, respectively. Purple dots indicate the top ten enriched pathways, darker dots indicate significant enrichment, lighter dots indicate enrichment but not significant, and larger areas indicate higher enrichment. The different color lines indicate the different pathway categories: blue for environmental information processing, purple for human disease, orange for metabolism, and yellow for organismal systems.

[45]. Although recent studies have demonstrated adaptive responses to oxidative stress, ROS remain indirect contributors to oxidative aging $[46,47]$. This situation is also consistent with our finding that GPD2 expression is upregulated with increasing age. The very specific metabolic patterns summarized above are helpful for understanding the potential mechanisms leading to aging.

Three of the 95 proteins that were differentially expressed in the different age groups were differentially expressed between men and women, but only among young people. This difference disappeared with aging. Studies have shown that aging does not proceed at a constant rate; there are inflection points during youth, middle age, and twilight age. Due to inconsistent proteomics results, Wyss-Coray et al. hypothesized that the aging rates of men and women also differ [19]. There are many pathways related to aging; the most studied of which are the insulin-like signaling pathway, the mTOR signaling pathway, the p53 signaling pathway, ferroptosis, and autophagy. Preliminary studies have shown that autophagy suppresses chromosomal instability by maintain- ing cellular metabolic homeostasis [48] and genomic instability is considered to be one of the nine characteristics of aging [49]. The occurrence of iron ion-dependent lipid peroxidation in cells is a marker of ferroptosis, which requires accumulation of iron ions, and blood iron metabolism influences healthy longevity [50]. Time-dependent excessive deposition of iron ions leads to genomic instability and DNA damage [51], and DNA damage can further promote aging. At the same time, excess iron ions inhibit expression of the protein $\mathrm{p} 53$, which can repair DNA damage, eventually initiating ferroptosis and accelerating aging [52]. Accumulation of excess iron ions in aging cells results in ferroptosis resistance, autophagy dysfunction, and evasion of the selfrenewal mechanism and accelerates organismal aging [53]. In summary, ferroptosis contributes to aging in multiple ways by affecting the $\mathrm{p} 53$ signaling pathway, increasing genomic instability, affecting autophagy, and increasing ROS accumulation. In our study, CP, a primary copper-binding protein and an important antioxidant [54] that prevents the production of free radicals [55], was identified as a DEP. 


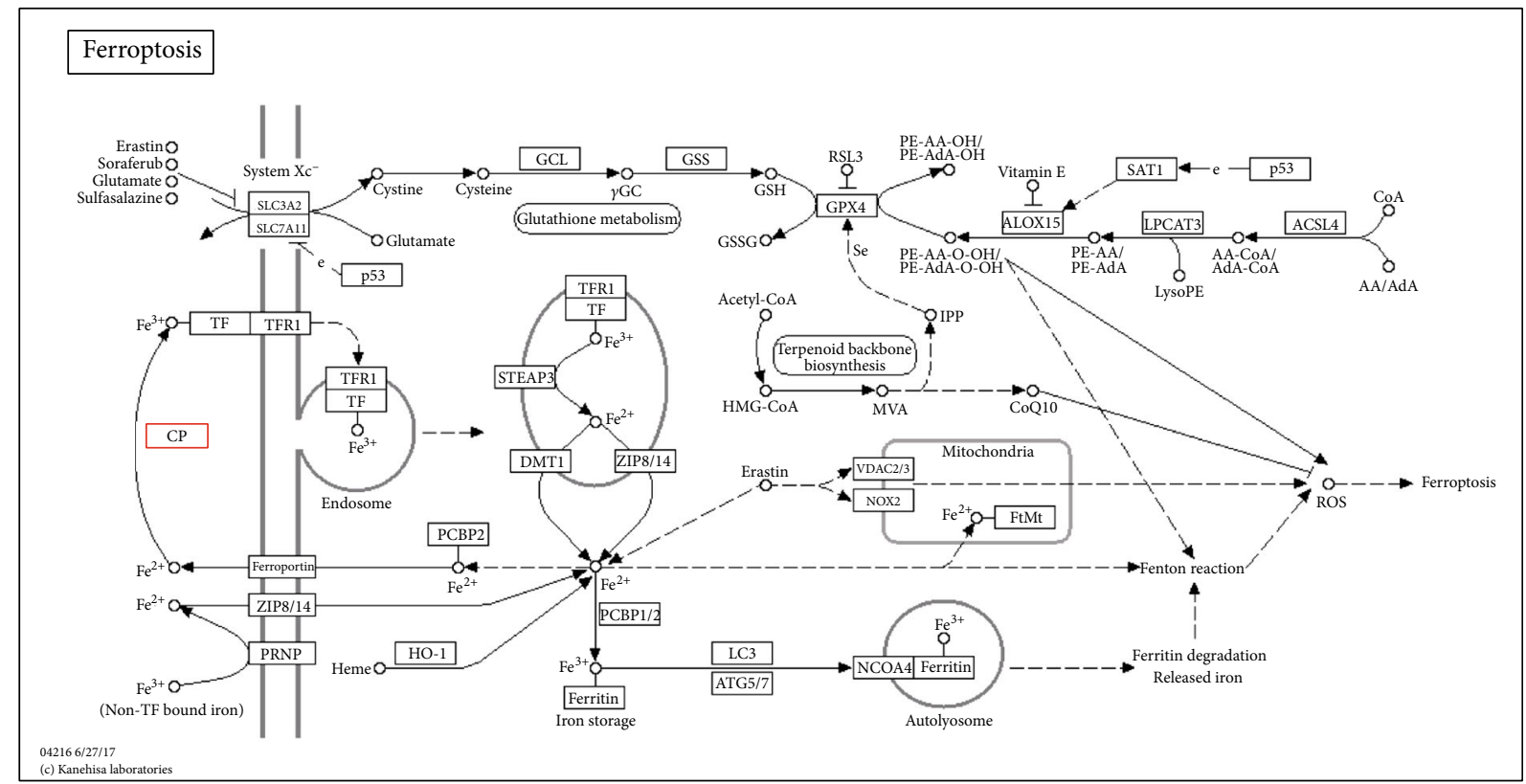

FIGURE 6: Changes in proteins in the Ferroptosis signaling pathway with aging. CP is a protein that is upregulated with aging and also highlights important gender differences with aging, and it plays an important role in this well-known cellular aging and death pathway.

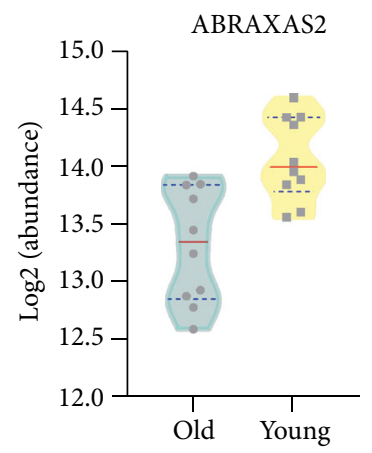

(a)

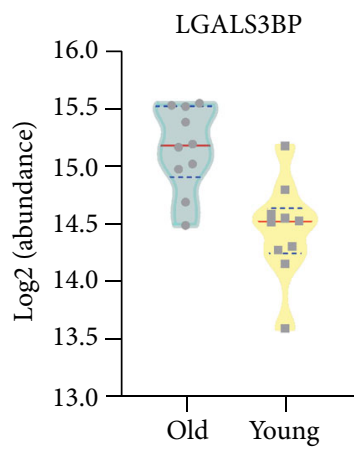

(b)

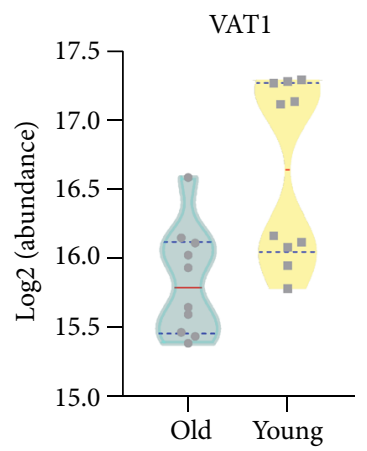

(c)

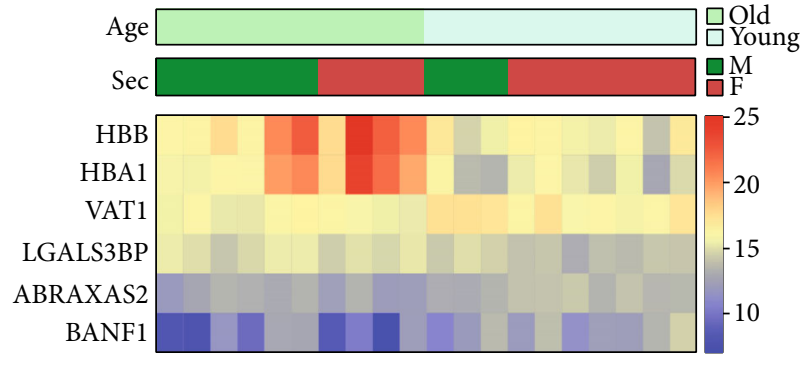

(d)

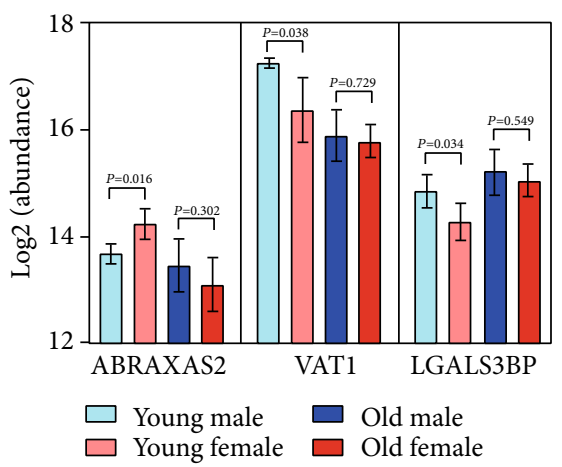

(e)

FIGURE 7: $(\mathrm{a}-\mathrm{c})$ Violin plots of the relative expression abundance of three proteins, ABRAXAS2, LGALS3BP, and VAT1, in the young-old group. The red solid line is the mean value and the blue dashed line is the quartile. The data in the vertical coordinates are protein expression abundance values taken as $\log ^{2}$. (d) Heatmap of six proteins of a particular value. (e) Mean values of the expression abundance of the three proteins in young and old males and females. The $p$ values between the groups are marked. It can be seen that the three proteins differ between young men and women and do not differ between older men and women. 


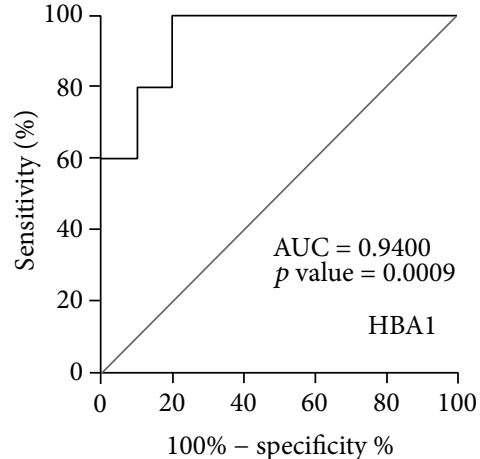

(a)

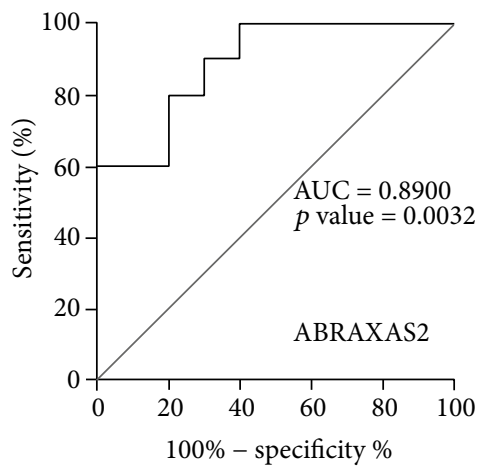

(d)

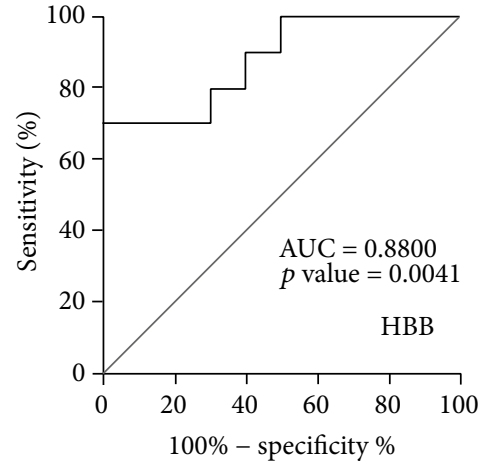

(b)

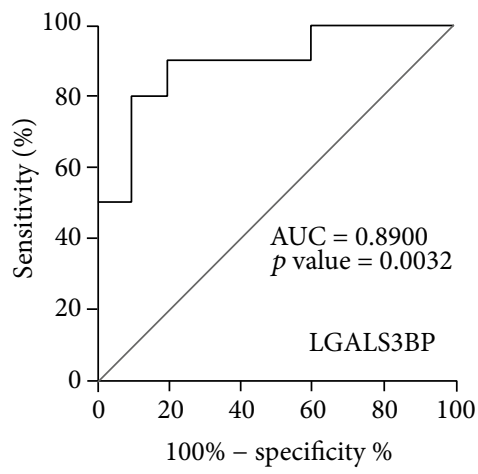

(e)

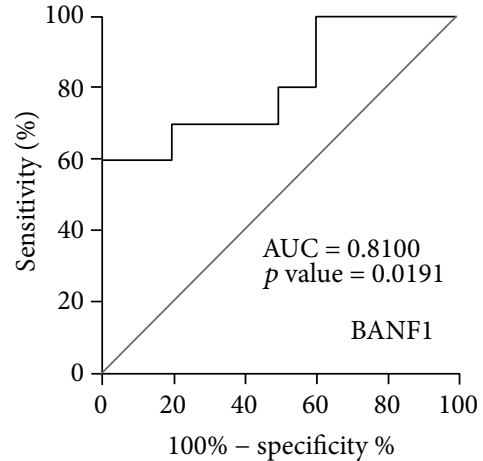

(c)

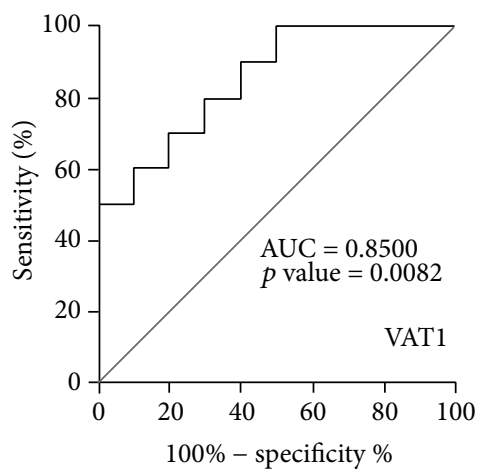

(f)

FIGURE 8: (a-f) Receiver operating characteristic curve (ROC curve) with an AUC and $p$ value obtained by comparing six proteins in young and older people.

TABLE 3: Different protein expressions at different ages in different genders. The $t$-test showed significant differences among age groups $\left({ }^{*} p<0.05\right)$ and between genders for ABRAXAS2, VAT1, and LGALS3BP $\left({ }^{* *} p<0.05\right)$. More details are described in Section 3 . The case group is an older group (55-70 years) and the control group is a young group (20-30 years). $M$ : mean protein expression of male; $F$ : mean protein expression of female.

\begin{tabular}{|c|c|c|c|c|c|c|c|}
\hline & Accession & ID & Description & Gene & $\begin{array}{l}\text { Old and young } \\
\text { differences }\end{array}$ & $\begin{array}{l}\text { Old group } \\
\text { differences in } \\
\text { genders }\end{array}$ & $\begin{array}{l}\text { Young group } \\
\text { differences in } \\
\text { genders }\end{array}$ \\
\hline \multirow{2}{*}{ Down } & Q15018 & $\begin{array}{l}\text { ABRX2- } \\
\text { HUMAN }\end{array}$ & $\begin{array}{c}\text { BRISC complex subunit } \\
\text { Abraxas } 2\end{array}$ & ABRAXAS2 & ${ }^{*} p=0.001$ & $\begin{array}{c}p=0.302 \\
M=13.45761365 \\
F=13.10540960\end{array}$ & $\begin{array}{c}{ }^{* *} p=0.016 \\
M=13.6814853567 \\
F=14.2325095143\end{array}$ \\
\hline & Q99536 & $\begin{array}{l}\text { VAT1_- } \\
\text { HUMAN }\end{array}$ & $\begin{array}{l}\text { Synaptic vesicle membrane } \\
\text { protein VAT-1 homolog }\end{array}$ & VAT1 & ${ }^{*} p=0.004$ & $\begin{array}{c}p=0.729 \\
M=15.87932308 \\
F=15.78413334\end{array}$ & $\begin{array}{c}{ }^{* *} p=0.038 \\
M=17.2356184533 \\
F=16.3622206371\end{array}$ \\
\hline Up & Q08380 & $\begin{array}{l}\text { LG3BP }_{-} \\
\text {HUMAN }\end{array}$ & Galectin-3-binding protein & LGALS3BP & ${ }^{*} p=0.001$ & $\begin{array}{c}p=0.549 \\
M=15.20773285 \\
F=15.01199494\end{array}$ & $\begin{array}{c}{ }^{* *} p=0.034 \\
M=14.8493189733 \\
F=14.2752645800\end{array}$ \\
\hline
\end{tabular}

$\mathrm{CP}$ has been shown to be associated with oxidative modifications in age-related changes [56] and with brain aging [32]. It is also involved in ferroptosis, an important signaling pathway associated with aging.

In our study, on the basis of $t$ tests, only 3 of the 95 DEPs between age groups had statistically significant sex differences and the differential expression of the 3 proteins between sexes existed only in young people. This finding may be related to the difference in the aging rate between men and women. Among the DEPs, ABRAXAS2, also known as ABRO1, is a scaffold protein that recruits a variety of peptides to assemble BRCC36 isopeptide complex (BRISC) deubiquitinating enzyme (DUB) complexes. It has been shown that inhibitors of DUBs can induce autophagy and thereby inhibit cell death [57]. The BRISC enzyme has deubiquitination activity and consists of four known subunits: MERIT40; BRE, which is expressed in the brain and reproductive organs; BRCA1/BRCA2 complex, subunit 3 (BRCC3); and ABRO1 [58]. BRCC3, which was also among the 95 DEPs that we identified, exhibited a relationship with 


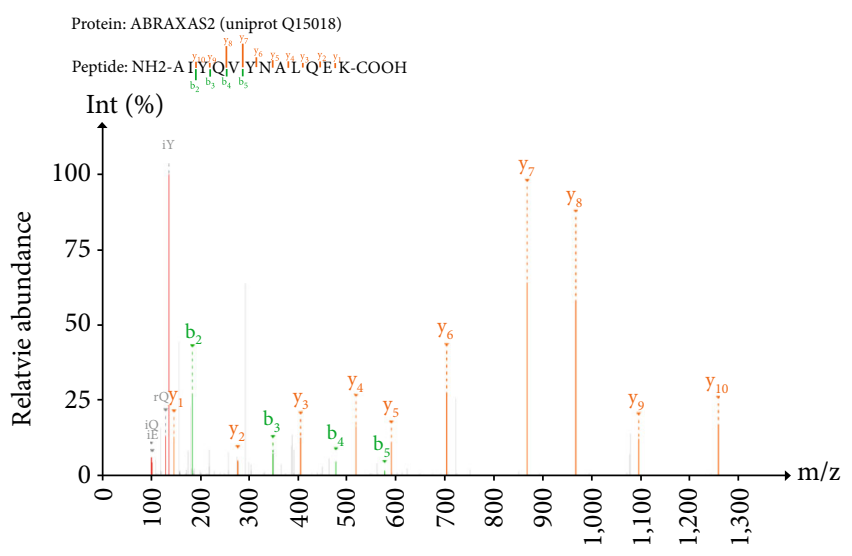

(a)

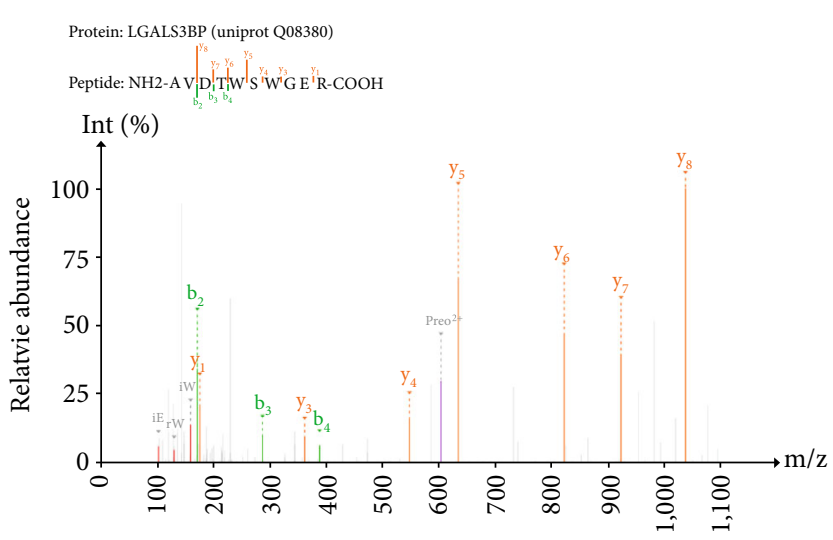

(b)

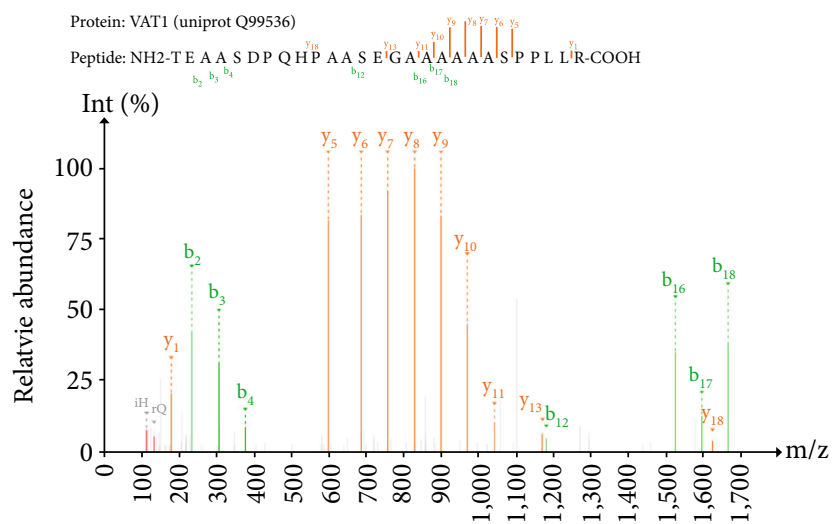

(c)

FIgure 9: (a) The sequence NH2-AIYQVYNALQEK-COOH allows the identification of ABRAXAS2. (b) The sequence NH2AVDTWSWGER-COOH allows the identification of LGALS3BP. (c) The sequence NH2-TEAASDPQHPAASEGAAAAAASPPLLR$\mathrm{COOH}$ allows the identification of VAT1.

ABRO1 and PSMB7 in the protein-protein interaction network. Excessive oxidative stress leads to aging [59], especially in the skin, which is the first line of defense against various types of external stimuli and is subject to oxidative stress. ABRO1, a newly discovered p53-dependent regulator, plays important roles in tumor suppression and the DNA damage response [60]; consistent with these roles, studies have pointed out that ABRO1 is related to telomere replication and genome repair [61]. A blocked chromosome replication fork is essential for the maintenance of chromosome stability. ABRO1 protects the integrity of the blocked replication fork and thus maintains the stability of the genome [62]. The expression of ABRO1 was downregulated with age in our study, and cells' ability to respond to oxidative stress decreases with age, which may imply that ABRO1 is an important indicator of aging. Second, VAT1 was expressed at high levels in the skin, with the overall expression being higher in males than females, which is consistent with results from the Human Protein Atlas (HPA) database (https://www .proteinatlas.org/ENSG00000108828-VAT1/tissue). VAT1 participates in calcium-regulated keratinocyte activation in the epidermal repair mechanism and has ATPase activity. During the EuKaryotic Orthologous Groups (KOG) analysis of our data, VAT1 was found to be enriched for the processes of energy production and conversion. Studies have shown that hVAT-1 plays a specific role in the physiology of keratinocytes, especially in the process of calcium regulation, and the gene encoding VAT1 is located on the BRCA1 locus $[63,64]$. It may also form the BRISC enzyme together with the aforementioned ABRO1 protein, which is involved in deubiquitination activities, while ubiquitination is involved in DNA repair and stabilization of protein complexes [65]. Proteasome activity is reduced during aging, in which ubiquitination is the target event. Some of the most important biological processes associated with skin aging are ubiquitin-induced proteolysis and cellular metabolism [66]. Therefore, we speculate that the downregulation of VAT1 and ABRO1 with age is an important marker of ubiquitination and even aging. Third, LGALS3BP, also known as Mac-2 binding protein (M2BP), is involved mainly in biological processes that promote integrin-mediated cell adhesion and platelet degranulation and may stimulate the host to defend against viruses and tumor cells. M2BP can combine with collagens IV, V, and VI and with fibronectin [67], and M2BP is significantly related to reactive oxygen metabolites [68]. Increases in ROS, platelet activation, adiponectin, and oxidative stress are important factors leading to aging. The functional relationship between $\mathrm{M} 2 \mathrm{BP}$ and aging needs further study. To date, no publications have reported the proteins ABRAXAS2, VAT1, and LGALS3BP as candidate 
biomarkers for aging. In addition, the differential expression of these proteins may suggest a difference in the rate of aging between men and women, but there are no data regarding the mechanisms by which imbalances in the three proteins play roles in skin aging.

In our experiments, we identified 95 age-differentiated proteins in the forearm skin of 20 healthy Chinese volunteers and 3 of them were key proteins that differed between age groups and sexes. Comparison of our results with the results of other studies designed to identify skin aging biomarkers revealed some differences that may be attributable to differences in regional categories, genetic factors, sex makeup, and sample processing during the experiment. Results that were highly consistent with the results of other studies were also obtained, which indicates the validity of the method and results of the current experiment. However, in the present experiment, more correlations than causal relationships were found, so further experimental confirmation is needed. In quantitative proteomics studies, posttranslational modifications of proteins are also worthy of attention and both protein glycosylation and protein carbamylation are hallmarks of aging $[69,70]$. Multiomics approaches will provide richer perspectives on aging than single proteomics techniques [71]. Multiomics analyses have been widely used for research on cancer [72] but have received very little application in the field of aging. Network-based integrated multiomics analyses may provide new insights into the nonlinear processes of aging and aid in the search for markers of inflection points.

\section{Conclusion}

We conducted an in-depth exploration of the epidermis based on a proteomics technology platform. We have demonstrated that our method is able to detect senescence- and sex-related epidermal proteins with significant differences, and we also found some candidate biomarkers that exhibit age-dependent sex differences. These results demonstrate the usefulness of our new proteomics assay for further elucidating biological processes, pathways, and biomarkers of skin aging. In conclusion, our findings indicate that the combination of noninvasive extraction of epidermal proteins and DIA mass spectrometry has great potential for future research in the field of skin health and disease.

\section{Data Availability}

Raw data can be obtained from corresponding authors.

\section{Additional Points}

Significance. We conducted a novel, noninvasive epidermal proteomics study in a healthy Chinese population. We identified numerous differentially expressed proteins, including the protein $\mathrm{CP}$, which was upregulated with age and is involved in a number of important signaling pathways related to aging, such as ferroptosis, the p53 signaling pathway, and ROS accumulation. Interestingly, through statistical analysis, we also found that there were trends toward sex differences in proteins that were differentially expressed during the aging process. We hope that these findings may provide new insights into the difference in the rate of aging between men and women. Most importantly, parts of our noninvasive epidermal proteomics data were consistent with convinced plasma proteomics data previously reported and can provide new insights for future proteomics studies on the noninvasive detection of skin aging and other epidermal conditions.

\section{Ethical Approval}

The present study was conducted in accordance with the recommendations of the Medical Ethics Committee of Anhui Medical University (reference no. PJ2016-03-02).

\section{Consent}

Written informed consent was obtained from all included subjects.

\section{Conflicts of Interest}

The authors declare no conflict of interest.

\section{Authors' Contributions}

All authors participated in the design and interpretation of the studies and review of the paper. SRC performed the research. SRC, HZ, and JM performed the data analysis. SY and XJZ designed the experimental strategy and guided the study. The paper was written by SRC and was approved by all authors. Shirui Chen and Hui Zhang contributed equally to this work.

\section{Acknowledgments}

We thank all the individuals who participated in this study and the First Affiliated Hospital of Anhui Medical University and the Institute of Dermatology of Anhui Medical University for their strong support. We also thank for BGI Tech Solutions Co. Ltd. for the technical assistance with mass spectrometry analysis work. The study was supported by a grant from the Science \& Technology Action Plans for the Prevention and Treatment of Major Diseases sponsored by the National Health and Family Planning Commission of the People's Republic of China (grant no. 2017ZX-01E-002) and Anhui Institute of Translational Medicine (ZHYX2020A005).

\section{Supplementary Materials}

Supplementary materials contain 8 tables. Table S1 shows 57 proteins that are significantly upregulated in the elderly relative to the young. Table $\mathrm{S} 2$ shows 38 proteins that are significantly downregulated in the elderly relative to the young. The functional classification involving molecular functions, biological processes, cellular components, and pathways of 95 proteins which are expressed in different age groups is shown in Table S3. Analysis of the KEGG pathway of 21 important proteins is shown in Table S4. Network analyst enrichment of Figures 3(b)-3(e) is shown in Table S5-8. (Supplementary Materials) 


\section{References}

[1] H. Baurecht, M. C. Rühlemann, E. Rodríguez et al., "Epidermal lipid composition, barrier integrity, and eczematous inflammation are associated with skin microbiome configuration," The Journal of Allergy and Clinical Immunology, vol. 141, no. 5, pp. 1668-1676.e16, 2018.

[2] X. Ding, W. Bloch, S. Iden et al., "mTORC1 and mTORC2 regulate skin morphogenesis and epidermal barrier formation," Nature Communications, vol. 7, no. 1, p. 13226, 2016.

[3] M. C. Velarde, "Epidermal barrier protects against ageassociated systemic inflammation," The Journal of Investigative Dermatology, vol. 137, no. 6, pp. 1206-1208, 2017.

[4] A. B. Kimball, M. B. Alora-Palli, M. Tamura et al., "Ageinduced and photoinduced changes in gene expression profiles in facial skin of Caucasian females across 6 decades of age," Journal of the American Academy of Dermatology, vol. 78, no. 1, pp. 29-39.e7, 2018.

[5] A. Kuehne, J. Hildebrand, J. Soehle et al., "An integrative metabolomics and transcriptomics study to identify metabolic alterations in aged skin of humans in vivo," BMC Genomics, vol. 18, no. 1, p. 169, 2017.

[6] R. Osborne, T. Hakozaki, T. Laughlin, and D. R. Finlay, "Application of genomics to breakthroughs in the cosmetic treatment of skin ageing and discoloration," The British Journal of Dermatology, vol. 166, Supplement 2, pp. 16-19, 2012.

[7] A. L. S. Chang, G. Atzmon, A. Bergman et al., "Identification of genes promoting skin youthfulness by genome-wide association study," The Journal of Investigative Dermatology, vol. 134, no. 3, pp. 651-657, 2014.

[8] H. D. de Koning, E. H. van den Bogaard, J. G. M. Bergboer et al., "Expression profile of cornified envelope structural proteins and keratinocyte differentiation-regulating proteins during skin barrier repair," The British Journal of Dermatology, vol. 166, no. 6, pp. 1245-1254, 2012.

[9] D. H. Lee, J. H. Oh, and J. H. Chung, "Glycosaminoglycan and proteoglycan in skin aging," Journal of Dermatological Science, vol. 83, no. 3, pp. 174-181, 2016.

[10] T. Kanaki, E. Makrantonaki, and C. C. Zouboulis, "Biomarkers of skin aging," Reviews in Endocrine \& Metabolic Disorders, vol. 17, no. 3, pp. 433-442, 2016.

[11] Z. Xu, J. Huo, X. Ding et al., "Coenzyme Q10 improves lipid metabolism and ameliorates obesity by regulating CaMKIImediated PDE4 inhibition," Scientific Reports, vol. 7, no. 1, pp. 8253-8253, 2017.

[12] A. Perl, " $m$ TOR activation is a biomarker and a central pathway to autoimmune disorders, cancer, obesity, and aging," Annals of the New York Academy of Sciences, vol. 1346, no. 1, pp. 33-44, 2015.

[13] Y.-H. Ho and S. Méndez-Ferrer, "Microenvironmental contributions to hematopoietic stem cell aging," Haematologica, vol. 105, no. 1, pp. 38-46, 2020.

[14] G. A. B. Marais, J. M. Gaillard, C. Vieira et al., "Sex gap in aging and longevity: can sex chromosomes play a role?," Biology of Sex Differences, vol. 9, no. 1, p. 33, 2018.

[15] A. Al-Attar, S. R. Presnell, C. A. Peterson, D. T. Thomas, and C. T. Lutz, "The effect of sex on immune cells in healthy aging: elderly women have more robust natural killer lymphocytes than do elderly men," Mechanisms of Ageing and Development, vol. 156, pp. 25-33, 2016.
[16] S. Seidenari, A. Pagnoni, A. Di Nardo, and A. Giannetti, "Echographic evaluation with image analysis of normal skin: variations according to age and sex," Skin Pharmacology, vol. 7, pp. 201-209, 2004.

[17] J. E. Oblong, "Comparison of the impact of environmental stress on male and female skin," The British Journal of Dermatology, vol. 166, Supplement 2, pp. 41-44, 2012.

[18] S. N. Austad and K. E. Fischer, "Sex differences in lifespan," Cell Metabolism, vol. 23, no. 6, pp. 1022-1033, 2016.

[19] B. Lehallier, D. Gate, N. Schaum et al., "Undulating changes in human plasma proteome profiles across the lifespan," Nature Medicine, vol. 25, no. 12, pp. 1843-1850, 2019.

[20] A. Azimi, P. Yang, M. Ali et al., "Data Independent Acquisition Proteomic Analysis Can Discriminate between Actinic Keratosis, Bowen's Disease, and Cutaneous Squamous Cell Carcinoma," The Journal of Investigative Dermatology, vol. 140, no. 1, pp. 212-222.e11, 2020.

[21] B. C. Collins, C. L. Hunter, Y. Liu et al., "Multi-laboratory assessment of reproducibility, qualitative and quantitative performance of SWATH-mass spectrometry," Nature Communications, vol. 8, no. 1, p. 291, 2017.

[22] N. J. Raine-Fenning, M. P. Brincat, and Y. Muscat-Baron, "Skin aging and menopause : implications for treatment," American Journal of Clinical Dermatology, vol. 4, no. 6, pp. 371-378, 2003.

[23] M. M. Bradford, "A rapid and sensitive method for the quantitation of microgram quantities of protein utilizing the principle of protein-dye binding," Analytical Biochemistry, vol. 72, no. 1-2, pp. 248-254, 1976.

[24] J. Cox and M. Mann, "MaxQuant enables high peptide identification rates, individualized p.p.b.-range mass accuracies and proteome-wide protein quantification," Nature Biotechnology, vol. 26, no. 12, pp. 1367-1372, 2008.

[25] R. Bruderer, O. M. Bernhardt, T. Gandhi et al., "Extending the limits of quantitative proteome profiling with dataindependent acquisition and application to acetaminophentreated three-dimensional liver microtissues," Molecular of Cellular Proteomics, vol. 14, no. 5, pp. 1400-1410, 2015.

[26] M. Choi, C. Y. Chang, T. Clough et al., "MSstats: an R package for statistical analysis of quantitative mass spectrometry-based proteomic experiments," Bioinformatics (Oxford, England), vol. 30, no. 17, pp. 2524-2526, 2014.

[27] J. Xia, E. E. Gill, and R. E. Hancock, "NetworkAnalyst for statistical, visual and network-based meta-analysis of gene expression data," Nature Protocols, vol. 10, no. 6, pp. 823844, 2015.

[28] G. Zhou, O. Soufan, J. Ewald, R. E. W. Hancock, N. Basu, and J. Xia, "NetworkAnalyst 3.0: a visual analytics platform for comprehensive gene expression profiling and meta-analysis," Nucleic Acids Research, vol. 47, no. W1, pp. W234w241, 2019.

[29] T. Tanaka, A. Biancotto, R. Moaddel et al., "Plasma proteomic signature of age in healthy humans," Aging Cell, vol. 17, no. 5, article e12799, 2018.

[30] N. Basisty, A. Kale, O. H. Jeon et al., "A proteomic atlas of senescence-associated secretomes for aging biomarker development," PLoS Biology, vol. 18, no. 1, article e3000599, 2020.

[31] G. Li, K. Y. Liu, and Z. P. Qiu, “An integrative module analysis of DNA methylation landscape in aging," Experimental and Therapeutic Medicine, vol. 17, pp. 3411-3416, 2019. 
[32] D. Wang, S. Liu, J. Warrell et al., "Comprehensive functional genomic resource and integrative model for the human brain," Science, vol. 362, no. 6420, article eaat8464, 2018.

[33] C. W. Levenson and N. M. Tassabehji, "Iron and ageing: an introduction to iron regulatory mechanisms," Ageing Research Reviews, vol. 3, no. 3, pp. 251-263, 2004.

[34] R. Ostan, D. Monti, P. Gueresi, M. Bussolotto, C. Franceschi, and G. Baggio, "Gender, aging and longevity in humans: an update of an intriguing/neglected scenario paving the way to a gender-specific medicine," Clinical Science (London, England), vol. 130, no. 19, pp. 1711-1725, 2016.

[35] T. L. Bale and C. N. Epperson, "Sex differences and stress across the lifespan," Nature Neuroscience, vol. 18, no. 10, pp. 1413-1420, 2015.

[36] K. E. Fischer and N. C. Riddle, "Sex differences in aging: genomic instability," The Journals of Gerontology. Series A, Biological Sciences and Medical Sciences, vol. 73, no. 2, pp. 166-174, 2018.

[37] J. Xu, Y. Ying, G. Xiong, L. Lai, Q. Wang, and Y. Yang, "Knockdown of serpin peptidase inhibitor clade $\mathrm{C}$ member 1 inhibits the growth of nasopharyngeal carcinoma cells," Molecular Medicine Reports, vol. 19, pp. 3658-3666, 2019.

[38] L. Fontana, L. Partridge, and V. D. Longo, "Extending healthy life span-from yeast to humans," Science, vol. 328, no. 5976, pp. 321-326, 2010.

[39] G. Perrot, C. Colin-Pierre, L. Ramont et al., "Decreased expression of GPC1 in human skin keratinocytes and epidermis during ageing," Experimental Gerontology, vol. 126, p. 110693 , 2019.

[40] E. Fuentes and I. Palomo, "Role of oxidative stress on platelet hyperreactivity during aging," Life Sciences, vol. 148, pp. 1723, 2016.

[41] S. Kim, H. S. Cheon, J. C. Song, S. M. Yun, S. I. Park, and J. P. Jeon, "Aging-related changes in mouse serum glycerophospholipid profiles," Osong Public Health and Research Perspectives, vol. 5, no. 6, pp. 345-350, 2014.

[42] A. G. Gunin, V. V. Petrov, N. N. Golubtzova, O. V. Vasilieva, and N. K. Kornilova, "Age-related changes in angiogenesis in human dermis," Experimental Gerontology, vol. 55, pp. 143151, 2014.

[43] R. Uzhachenko, K. Boyd, D. Olivares-Villagomez et al., "Mitochondrial protein Fus1/Tusc2 in premature aging and agerelated pathologies: critical roles of calcium and energy homeostasis," Aging (Albany NY), vol. 9, no. 3, pp. 627-649, 2017.

[44] L. Yuan, L. Zhai, L. Qian et al., "Switching off IMMP2L signaling drives senescence via simultaneous metabolic alteration and blockage of cell death," Cell Research, vol. 28, no. 6, pp. 625-643, 2018.

[45] M. M. Kamiński, S. W. Sauer, M. Kamiński et al., “T cell activation is driven by an ADP-dependent glucokinase linking enhanced glycolysis with mitochondrial reactive oxygen species generation," Cell Reports, vol. 2, no. 5, pp. 1300-1315, 2012.

[46] A. Kammeyer and R. M. Luiten, "Oxidation events and skin aging," Ageing Research Reviews, vol. 21, pp. 16-29, 2015.

[47] G. Lenaz, C. Bovina, M. D'aurelio et al., "Role of mitochondria in oxidative stress and aging," Annals of the New York Academy of Sciences, vol. 959, no. 1, pp. 199-213, 2002.

[48] R. Mathew, S. Kongara, B. Beaudoin et al., "Autophagy suppresses tumor progression by limiting chromosomal instabil- ity," Genes \& Development, vol. 21, no. 11, pp. 1367-1381, 2007.

[49] C. López-Otín, M. A. Blasco, L. Partridge, M. Serrano, and G. Kroemer, "The hallmarks of aging," Cell, vol. 153, no. 6, pp. 1194-1217, 2013.

[50] P. R. H. J. Timmers, J. F. Wilson, P. K. Joshi, and J. Deelen, "Multivariate genomic scan implicates novel loci and haem metabolism in human ageing," Nature Communications, vol. 11, no. 1, p. 3570, 2020.

[51] I. G. Mollet, D. Patel, F. S. Govani et al., "Low dose iron treatments induce a DNA damage response in human endothelial cells within minutes," PLoS One, vol. 11, no. 2, article e0147990, 2016.

[52] J. H. Park, J. Zhuang, J. Li, and P. M. Hwang, "p53 as guardian of the mitochondrial genome," FEBS Letters, vol. 590, no. 7, pp. 924-934, 2016.

[53] S. Masaldan, S. A. S. Clatworthy, C. Gamell et al., "Iron accumulation in senescent cells is coupled with impaired ferritinophagy and inhibition of ferroptosis," Redox Biology, vol. 14, pp. 100-115, 2018.

[54] M. Aouffen, J. Paquin, E. De Grandpré, R. Nadeau, and M. A. Mateescu, "Deglycosylated ceruloplasmin maintains its enzymatic, antioxidant, cardioprotective, and neuronoprotective properties," Biochemistry and Cell Biology, vol. 79, no. 4, pp. 489-497, 2001.

[55] B. Wang and X. P. Wang, "Does ceruloplasmin defend against neurodegenerative diseases?," Current Neuropharmacology, vol. 17, no. 6, pp. 539-549, 2019.

[56] G. Musci, M. C. B. di Patti, U. Fagiolo, and L. Calabrese, "Agerelated changes in human ceruloplasmin. Evidence for oxidative modifications," The Journal of Biological Chemistry, vol. 268, no. 18, pp. 13388-13395, 1993.

[57] J. Chen, X. Chen, D. Xu et al., “Autophagy induced by proteasomal DUB inhibitor NiPT restricts NiPT-mediated cancer cell death," Frontiers in Oncology, vol. 10, pp. 348-348, 2020.

[58] L. Cilenti, M. P. Balakrishnan, X. L. Wang et al., "Regulation of Abro1/KIAA0157 during myocardial infarction and cell death reveals a novel cardioprotective mechanism for Lys63-specific deubiquitination," Journal of Molecular and Cellular Cardiology, vol. 50, no. 4, pp. 652-661, 2011.

[59] M. Rinnerthaler, J. Bischof, M. K. Streubel, A. Trost, and K. Richter, "Oxidative stress in aging human skin," Biomolecules, vol. 5, no. 2, pp. 545-589, 2015.

[60] J. Zhang, M. Cao, J. Dong et al., “ABRO1 suppresses tumourigenesis and regulates the DNA damage response by stabilizing p53," Nature Communications, vol. 5, no. 1, p. 5059, 2014.

[61] E. Tripathi and S. Smith, "Cell cycle-regulated ubiquitination of tankyrase 1 by RNF8 and ABRO1/BRCC36 controls the timing of sister telomere resolution," The EMBO Journal, vol. 36, no. 4, pp. 503-519, 2017.

[62] S. Xu, X. Wu, L. Wu et al., "Abro1 maintains genome stability and limits replication stress by protecting replication fork stability," Genes \& Development, vol. 31, no. 14, pp. 1469-1482, 2017.

[63] J. Koch, J. Foekens, M. Timmermans et al., "Human VAT-1: a calcium-regulated activation marker of human epithelial cells," Archives of Dermatological Research, vol. 295, no. 5, pp. 203-210, 2003.

[64] K. Hayess, R. Kraft, J. Sachsinger et al., "Mammalian protein homologous to VAT-1 of Torpedo californica: isolation from Ehrlich ascites tumor cells, biochemical characterization, and 
organization of its gene," Journal of Cellular Biochemistry, vol. 69, no. 3, pp. 304-315, 1998.

[65] J. Grillari, H. Katinger, and R. Voglauer, "Aging and the ubiquitinome: traditional and non-traditional functions of ubiquitin in aging cells and tissues," Experimental Gerontology, vol. 41, no. 11, pp. 1067-1079, 2006.

[66] B. C. Capell, B. E. Tlougan, and S. J. Orlow, "From the rarest to the most common: insights from progeroid syndromes into skin cancer and aging," The Journal of Investigative Dermatology, vol. 129, no. 10, pp. 2340-2350, 2009.

[67] T. Sasaki, C. Brakebusch, J. Engel, and R. Timpl, “Mac-2 binding protein is a cell-adhesive protein of the extracellular matrix which self-assembles into ring-like structures and binds beta1 integrins, collagens and fibronectin," The EMBO Journal, vol. 17, no. 6, pp. 1606-1613, 1998.

[68] T. Sugiura, Y. Dohi, H. Takase et al., "Serum levels of Mac-2 binding protein increase with cardiovascular risk and reflect silent atherosclerosis," Atherosclerosis, vol. 251, pp. 192-196, 2016.

[69] L. Gorisse, C. Pietrement, V. Vuiblet et al., "Protein carbamylation is a hallmark of aging," Proceedings of the National Academy of Sciences of the United States of America, vol. 113, no. 5, pp. 1191-1196, 2016.

[70] C. Nicolas, S. Jaisson, L. Gorisse et al., "Carbamylation and glycation compete for collagen molecular aging in vivo," Scientific Reports, vol. 9, no. 1, p. 18291, 2019.

[71] N. Holzscheck, J. Söhle, B. Kristof et al., "Multi-omics network analysis reveals distinct stages in the human aging progression in epidermal tissue," Aging (Albany NY), vol. 12, no. 12, pp. 12393-12409, 2020.

[72] E. Bavafaye Haghighi, M. Knudsen, B. Elmedal Laursen, and S. Besenbacher, "Hierarchical classification of cancers of unknown primary using multi-omics data," Cancer Inform, vol. 18, pp. 117693511987216-1176935119872163, 2019. 